\title{
A Two-Dimensional MEMS Scanning Mirror Using Hybrid Actuation Mechanisms With Low Operation Voltage
}

\author{
Kah How Koh, Student Member, IEEE, and Chengkuo Lee, Member, IEEE
}

\begin{abstract}
This paper presents the design, fabrication, and characterization of a novel CMOS-compatible 2-D MEMS scanning mirror based on hybrid actuation mechanisms. Both electrothermal and electromagnetic (EM) actuations have been integrated in the same device for slow and fast scanning purposes, respectively. The added advantage of a CMOS-compatible fabrication process allows our device to be monolithically integrated with CMOS integrated circuits. Optical deflection angles of $\pm 1.5^{\circ}$ for a $74-\mathrm{Hz}$ vertical scan at $12 \mathrm{~mW}$ by electrothermal actuation and $\pm 10^{\circ}$ for a horizontal scan frequency of $202 \mathrm{~Hz}$ at $1.26 \mathrm{~mA}$ and $1 \mathrm{~V}_{\mathrm{ac}}$ by EM actuation are reported. Our unique design of utilizing both electrothermal and EM actuation mechanisms is the first demonstration of such hybrid-driven CMOS-compatible MEMS mirror. Various Lissajous patterns have been demonstrated at low-power biasing condition, making our proposed hybrid actuation design approach suitable for mobile 2-D raster scanning applications powered by batteries with limited capacity.

[2012-0019]
\end{abstract}

Index Terms-CMOS compatible, hybrid actuation, microelectromechanical systems (MEMS), mirror, optical MEMS.

\section{INTRODUCTION}

$\mathbf{M}$ ICROELECTROMECHANICAL systems (MEMS) technology has demonstrated to be indispensible in numerous applications such as energy harvesting [1], radio frequency (RF) communication [2], switch [3], inertial [4], and pressure sensing [5]. In the optical regime, MEMS technology has also been an enabling tool for numerous cutting-edge devices for optical communication [6]-[12] and imaging [13]-[20]. Cornerstones for the emergence of optical MEMS technology include actuator technology, optics design, and the development of movable or tunable micromechanical elements. The combinations of these elements enable optical MEMS devices to perform unique and sophisticated functions such as beam steering and attenuation for optical communication,

Manuscript received January 18, 2012; revised March 1, 2012; accepted April 4, 2012. Date of publication May 22, 2012; date of current version September 27, 2012. This work was supported by the National University of Singapore under Grant R-263-000-598-112 and A*STAR SERC Grants 0921010049, 1021650084, and 1021010022. The work of K. H. Koh was supported by a Ph.D. scholarship grant from GlobalFoundries, Singapore. Subject Editor H. Zappe.

This paper has supplementary downloadable multimedia material available at http://ieeexplore.ieee.org, provided by the authors. The material consists of an MPEG video demonstrating the Lissajous scan pattern generated from the authors' scanning mirror device.

The authors are with the Department of Electrical and Computer Engineering, National University of Singapore, Singapore 117576 (e-mail: kohkahhow@gmail.com; elelc@nus.edu.sg).

Color versions of one or more of the figures in this paper are available online at http://ieeexplore.ieee.org.

Digital Object Identifier 10.1109/JMEMS.2012.2196497 raster scanning for image display, micromechanical sensing, and optical filtering.

As a prelude to the discussion of hybrid actuation mechanisms, it is worthwhile to recall the various kinds of mainstream actuation techniques that are commonly used in the field of optical MEMS. These actuation mechanisms include electrostatic [21]-[31], electrothermal [32]-[37], electromagnetic (EM) [38]-[44], and piezoelectric [45]-[51]. Due to the limited material selection in CMOS manufacturing line and CMOS-compatible processes, actuation schemes to drive these silicon-based actuators have often been restricted to that of electrostatic, electrothemal, and EM [52]-[55]. Electrostatic actuation has been commonly adopted due to its extremely low power consumption and wide implementation in the form of vertical combs [21]-[28] or parallel plate configuration [29], [30]. However, electrostatic actuation faces many challenging issues such as low mechanical stability due to pull-in, nonlinearity, and a very high actuation voltage.

In the case of electrothermal driven MEMS mirrors, the electrothermal actuator often makes use of the varying degree of thermal expansion for two or more materials to achieve mechanical actuation. These electrothermal bimorph actuators provide a large static mechanical deflection angle to the mirror plate at a relatively low driving voltage. However, electrothermal actuation often operates in nonresonant or low resonant frequency condition due to their slow thermal response. On the other hand, EM actuated MEMS mirrors are able to operate in high frequency resonant conditions due to the use of an external ac excitation electrocoil. Commonly adopted design configurations for these EM driven mirror devices include the implementation of micrometer-sized EM coils [38]-[41] and electroplated ferromagnetic films on the frames of the devices [42]-[44]. Nevertheless, the need for an external EM coil or permanent magnet may result in bulky packaging.

Based on the various actuation mechanisms described earlier, several research groups have successfully demonstrated 2-D scanning based on a single mirror device approach. In the application of image projection display, Tani et al. demonstrated stable and wide-range 2-D scan by combining resonant motion for the fast horizontal scan $(11.2 \mathrm{kHz}$ and optical angle of $39^{\circ}$ ) and quasi-static operation for the slow vertical scan $\left(60 \mathrm{~Hz}\right.$ and optical angle of $29^{\circ}$ ) on a single piezoelectric driven MEMS mirror [51]. In the same year, Yalcinkaya et al. reported a state-of-the-art EM actuated 2-D MEMS mirror for high-resolution displays, with full optical scan angles of $65^{\circ}$ and $53^{\circ}$ achieved for the slow $(60 \mathrm{~Hz}$, sawtooth) and the fast 
(21.3 kHz, sinusoid) scanning, respectively [39]. This feat was later replicated by $\mathrm{Chu}$ and Hane, when their electrostatic driven 2-D microscanner was able to achieve the slow and the fast scanning at $162 \mathrm{~Hz}$ and $14^{\circ}$ and at $40 \mathrm{kHz}$ and $11.5^{\circ}$, respectively, in vacuum condition [24].

The approach of using two 1-D MEMS mirrors to achieve 2-D scanning has also gathered popularity in recent years as the design of the actuation mechanism for the fast and the slow scanning axis can now be decoupled, hence allowing the fast scanning MEMS mirror to achieve much better performance in terms of scan rate and optical scan angle. For example, Arslan et al. have successfully demonstrated a torsional combdriven 1-D microscanner that is able to achieve a $76^{\circ}$ total optical scan angle at $21.8 \mathrm{kHz}$ and $196 \mathrm{~V}_{\mathrm{pp}}$ [27]. Similarly, Isamoto et al. have also reported an electrostatic 1-D MEMS mirror scanning at $69.7 \mathrm{kHz}$, with an optical scan angle of $6.5^{\circ}$ [31]. More recently, Baran et al. developed a resonant 1-D piezoelectric microscanner that operates at $40 \mathrm{kHz}$ and at a $24-\mathrm{V}$ peak voltage, giving an optical scan angle of $38.5^{\circ}$ [49]. These aforementioned works demonstrate the feasibility of utilizing mechanical mode amplification to achieve enhanced performance. However, without proper design consideration, these fast scanning devices will suffer from high dynamic mirror deformation.

Hybrid actuation mechanisms, i.e., the combination of two or more of the aforementioned four actuation mechanisms, have already been demonstrated in various kinds of MEMS devices such as RF switches [56], energy harvesters [57], [58], and mirrors [59], [60]. The combination of both EM and electrostatic actuation mechanisms in the RF switch design proposed in [56] by Cho et al. allows them to achieve excellent switching characteristics at low power and voltage. Similarly, for both the cases of energy harvesters in [57] and [58] where hybrid energy harvesting mechanisms are investigated, these devices demonstrated higher output power density when both the piezoelectric and EM elements are deployed.

In this paper, we propose to leverage on the concept of mechanical amplification adopted in the design of the 1-D microscanner in [27] and demonstrate 2-D scanning using the single mirror approach instead. In addition, both electrothermal and EM actuation mechanisms will be integrated in our proofof-concept MEMS mirror design. This approach differs greatly from most of the 2-D scanning mirror designs already reported in the literature where the same actuation mechanism is often used to drive both the orthogonal scanning axes of the devices [21]-[51]. Unlike the hybrid actuation approach taken on by Li et al. in [59] and [60] where electrostatic comb drive actuators were used for the fast scanning actuation in their fabricated mirror devices, we have adopted EM actuation for our fast scanning axis in our mirror design. This is primarily due to the low actuation voltage and CMOS compatibility which EM actuation offers, hence allowing for the ease of monolithic integration with CMOS integrated circuit and lowering the fabrication cost. The slow scanning axis will be driven by electrothermal actuators as they have a large static or dynamic displacement characteristic at low resonant condition. Such hybrid actuation scheme proposed in our design allows for fast line scan driven by EM actuators operating at mechanical resonance condition

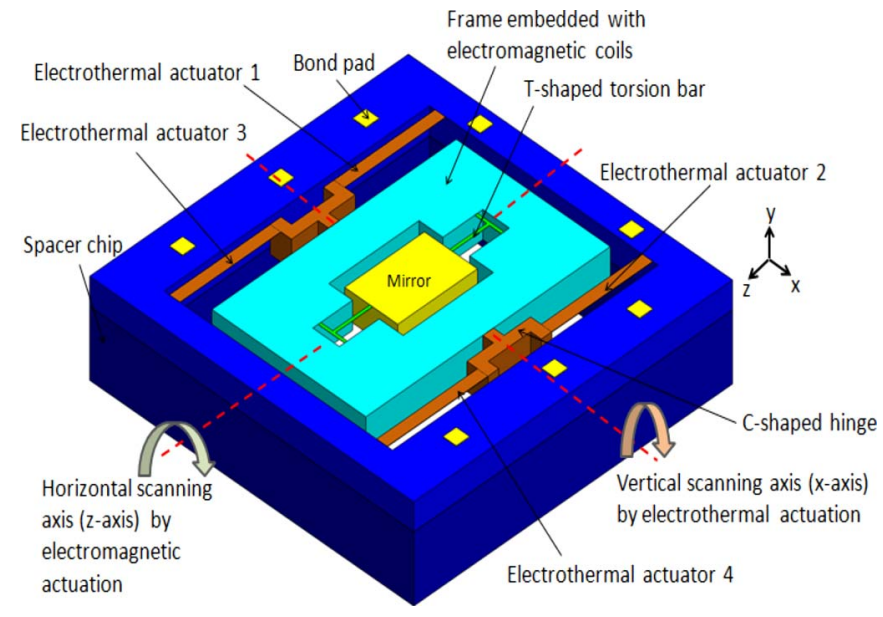

Fig. 1. Schematic drawing of the proposed 2-D MEMS scanning mirror incorporated with hybrid actuation mechanisms. The vertical and horizontal scanning motions are driven by electrothermal and EM actuation mechanisms, respectively.

to be produced on the horizontal axis, while a slower sweep, i.e., frame rate, driven by electrothermal actuators is produced on the orthogonal vertical axis. As such, our unique design of using both electrothermal and EM actuators, as well as mechanical amplification mechanism to excite 2-D raster scanning, is the first demonstration of such hybrid-driven CMOS-compatible MEMS mirror.

\section{DESIGN AND Modeling}

A schematic diagram of the proposed 2-D MEMS scanning mirror incorporating hybrid actuation mechanisms is shown in Fig. 1. There are four sets of electrothermal actuators responsible for the slow scanning about the horizontal axis, i.e., $x$-axis. The electrothermal actuators are anchored to the substrate and are joined to the frame by $\mathrm{C}$-shaped rigid hinges. EM coils are embedded in the frame and, in the presence of current flow and magnetic field, will generate a mechanical torque, producing fast scanning about the horizontal axis, i.e., $z$-axis. The mechanical energy from the EM actuation is coupled to the mirror plate through the T-shaped torsion bar. The details of the working principle and the modeling for both the electrothermal and the EM actuation will ensue on in this section.

\section{A. Electrothermal Actuation}

The design of the electrothermal actuator is shown in Fig. 2(a). It consists of a silicon ( $\mathrm{Si}$ ) cantilever made from the device layer of a silicon-on-insulator (SOI) wafer and aluminum (Al) heater deposited and patterned on it. As shown in the inset of Fig. 2(a), the Al heater is patterned in a winding manner so as to increase the resistance and thermal reliability of the heater and actuator, respectively. There are a total of $22 \mathrm{Al}$ windings designed to have a resistance of $500 \Omega$. A thin layer of $\mathrm{SiO}_{2}$, which acts as thermal insulation, is deposited around Al to increase the actuation efficiency. Together with the Si device layer used in the cantilever structure, the Al heater also functions as the other bimorph material for thermal actuation. When a current flows through the windings, the Al heats up and expands more than silicon, causing the actuator to bend 
(a) Room temperature

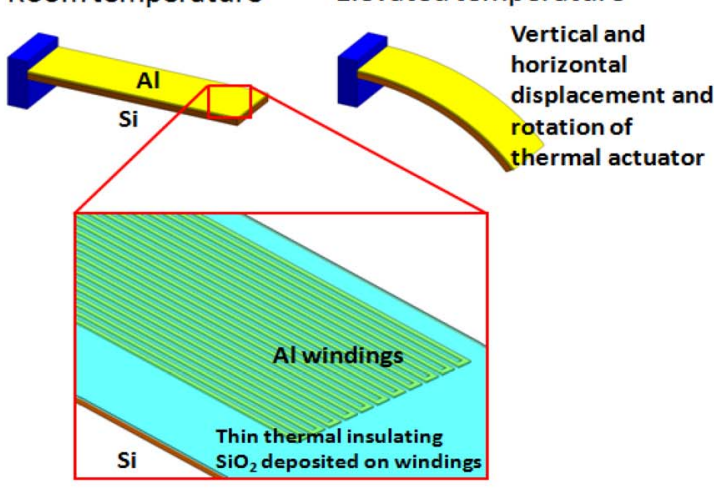

(b) Mechanical torque generated Electrothermal

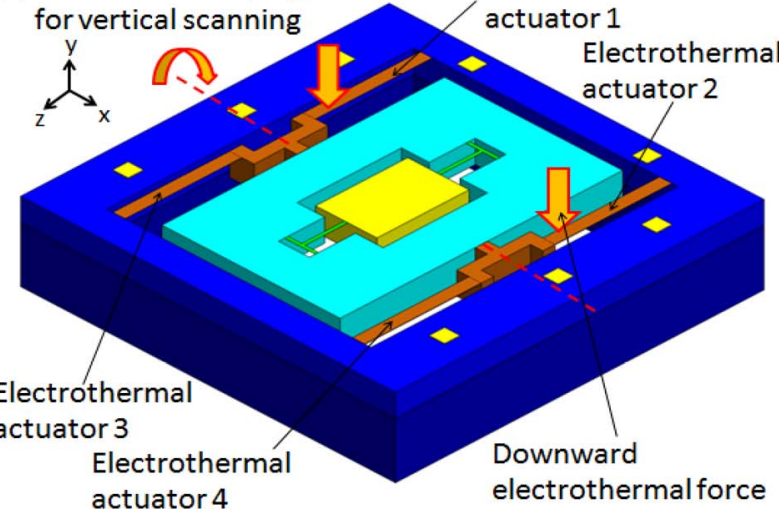

Fig. 2. Schematic drawing illustrating the (a) proposed electrothermal bimorph actuator made of $\mathrm{Al}$ and $\mathrm{Si}$, with the inset showing the winding design of the $\mathrm{Al}$ metal layer and thin thermal insulating $\mathrm{SiO}_{2}$ deposited around the windings, and (b) working principle of electrothermal actuation and rotation about the vertical scanning axis, i.e., $x$-axis, when electrothermal actuators 1 and 2 are biased serially to give a mechanical torque.

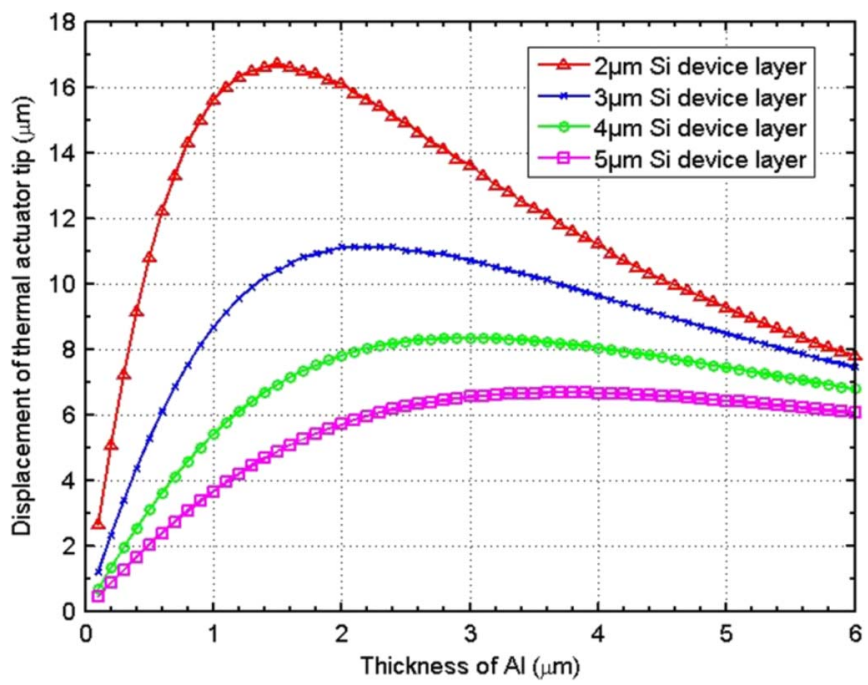

Fig. 3. Simulated plot illustrating the change in the tip displacement of a single clamped electrothermal actuator for a unit temperature change. The thickness of the Al metal layer is varied from 0.1 to $6 \mu \mathrm{m}$ for different $\mathrm{Si}$ device layer thicknesses of a SOI wafer.

downward. To obtain the desired rotating orientation of the mirror, selective biasing and bending of the four sets of electrothermal actuators can be made. For example, to achieve vertical scanning about the $x$-axis as shown in Fig. 2(b), actuators 1 and 2 are biased serially so that both the actuators experience downward displacements simultaneously, hence introducing a mechanical torque about the $x$-axis. Electronic control may be utilized to phase lock the biasing of the actuators such that there is a $180^{\circ}$ phase delay between the voltage bias for actuators 1 and 2 with 3 and 4 . This will enable bidirectional scanning capability, hence increasing the range of scanning.

Prior to fabrication, optimization based on mathematical modeling is done to determine the effect of the thickness of the $\mathrm{Si}$ device layer of a SOI wafer and $\mathrm{Al}$ layer on the performance of the actuator. The tip displacement of a typical bimorph beam

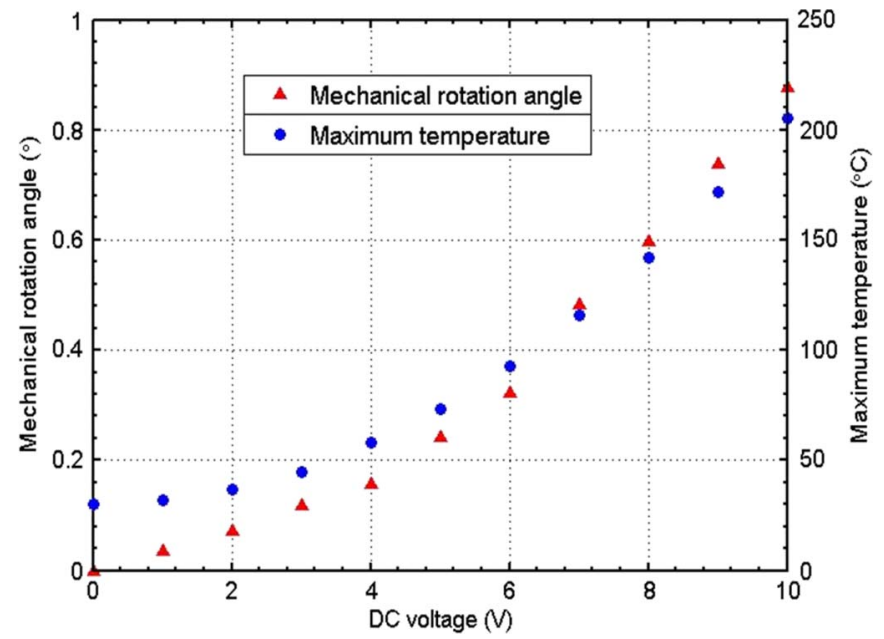

Fig. 4. Plots of mechanical rotation angle and maximum temperature of device versus total dc voltage applied to actuators 1 and 2. Results are obtained from FEM simulation using ANSYS.

of $\mathrm{Al}$ and $\mathrm{Si}$ under a strain mismatch has been readily derived in (1), shown at the bottom of the page, where $\delta$ is the tip displacement of a bimorph beam, $w_{A l}$ and $w_{S i}$ are the widths of the $\mathrm{Al}(200 \mu \mathrm{m})$ and $\mathrm{Si}(200 \mu \mathrm{m})$ layers, respectively, $E_{A l}$ and $E_{S i}$ are the Young's moduli of $\mathrm{Al}(65 \mathrm{GPa})$ and $\mathrm{Si}(162 \mathrm{GPa})$, respectively, $\alpha_{A l}$ and $\alpha_{S i}$ are the coefficients of thermal expansion of $\mathrm{Al}\left(2.6 \times 10^{-6} \mathrm{~K}^{-1}\right)$ and $\mathrm{Si}\left(23.1 \times 10^{-6} \mathrm{~K}^{-1}\right)$, respectively, $L$ is the length of the beam $(2.1 \mathrm{~mm}), \Delta T$ is the temperature change, and $t_{A l}$ and $t_{S i}$ are the thicknesses of the $\mathrm{Al}$ and Si layers, respectively [61]. Using (1), the displacement change at the tip of the bimorph beam actuator for different bimorph material thicknesses is analyzed and plotted in Fig. 3. As evident from Fig. 3, a thinner Si layer will give rise to better actuator performance. However, the tradeoff lies in the mechanical stability of the actuator as a thin $\mathrm{Si}$ cantilever breaks off from its anchor region easily. In view of these considerations, we started our fabrication using SOI

$$
\delta=\frac{3 w_{S i} w_{A l} E_{S i} E_{A l} t_{S i} t_{A l}\left(t_{S i}+t_{A l}\right)\left(\alpha_{A l}-\alpha_{S i}\right) \Delta T L^{2}}{\left(E_{A l} W_{A l} t_{A l}^{2}\right)^{2}+\left(E_{S i} W_{S i} t_{S i}^{2}\right)^{2}+2 w_{S i} w_{A l} E_{S i} E_{A l} t_{S i} t_{A l}\left(2 t_{A l}^{2}+3 t_{S i} t_{A l}+2 t_{S i}^{2}\right)}
$$


TABLE I

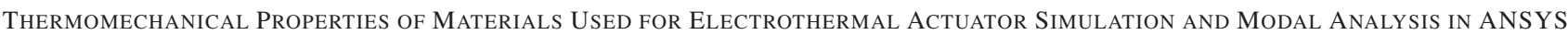

\begin{tabular}{ccccccc}
\hline \hline $\begin{array}{c}\text { Thin film } \\
\text { materials }\end{array}$ & $\begin{array}{c}\text { Density } \\
\left(\mathrm{kgm}^{-3}\right)\end{array}$ & $\begin{array}{c}\text { Young's Modulus } \\
\left(10^{9} \mathrm{~Pa}\right)\end{array}$ & $\begin{array}{c}\text { Poisson } \\
\text { ratio }\end{array}$ & $\begin{array}{c}\text { Thermal conductivity } \\
\left(\mathrm{Wm}^{-1} \mathrm{~K}^{-1}\right)\end{array}$ & $\begin{array}{c}\text { Coefficient of thermal } \\
\text { expansion }\left(10^{-6} \mathrm{~K}^{-1}\right)\end{array}$ & $\begin{array}{c}\text { Resistivity } \\
\left(10^{-3} \Omega \mathrm{m}\right)\end{array}$ \\
\hline $\mathrm{Al}$ & 2700 & 65 & 0.33 & 237 & 23.1 & $2.82 \times 10^{-5}$ \\
$\mathrm{SiO}_{2}$ & 2200 & 74 & 0.17 & 1.04 & 0.4 & $1 \times 10^{19}$ \\
$\mathrm{Si}$ & 2330 & 162 & 0.28 & 150 & 2.6 & 100 \\
\hline \hline
\end{tabular}

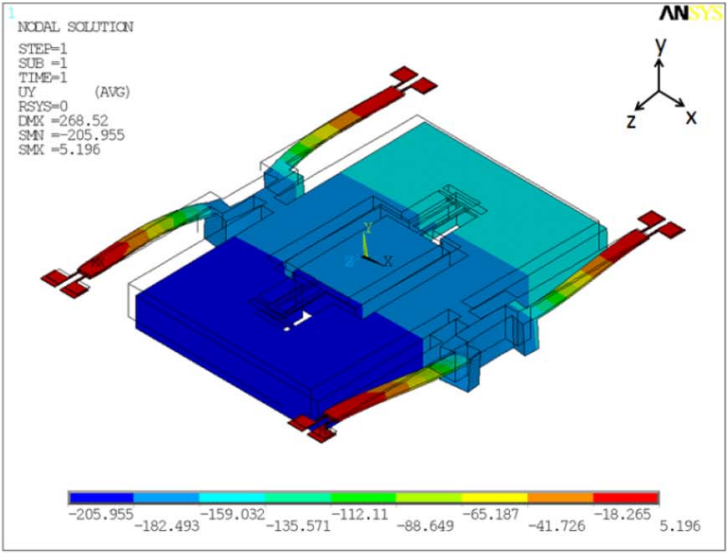

(a)

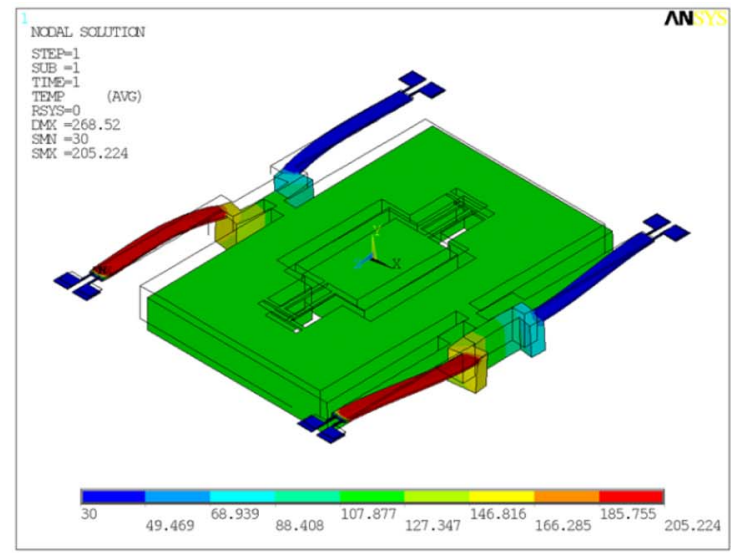

(b)

Fig. 5. Simulation result by ANSYS when actuators 3 and 4 are biased with a total dc voltage of $10 \mathrm{~V}$. (a) Y-displacement profile of the device where the mirror rotates about the $x$-axis. (b) Temperature distribution profile of the device.

wafers with a 3- $\mu$ m-thick Si device layer for added mechanical stability as well as reasonable actuator performance. Aside from investigating the influence of $\mathrm{Si}$ device layer thickness on the actuator performance, the impact of Al thickness on the actuator displacement is examined as well. For a Si device layer thickness of $3 \mu \mathrm{m}$, an optimal Al thickness of $2 \mu \mathrm{m}$ yields maximum actuator performance. This leads us to use a thickness of $2 \mu \mathrm{m}$ for our $\mathrm{Al}$ windings during the fabrication process.

Finite-element method (FEM) based on the proposed electrothermal actuator design is made using ANSYS simulation software. Fig. 4 shows the simulated plots of mechanical rotation angle and maximum temperature of device versus the total dc voltage applied to actuators 1 and 2 . As the dc voltage applied to actuators 1 and 2 increases, the mechanical rotation of the mirror and the maximum temperature of the actuator increase. These trends are expected as increase in current flow will result in greater actuator displacement and heating effect. More importantly, a maximum simulated temperature of $205^{\circ} \mathrm{C}$, which is well below the melting point of $\mathrm{Al}$, is obtained at $10 \mathrm{~V}_{\mathrm{dc}}$. This signifies good device reliability within the bias range of $10 \mathrm{~V}_{\mathrm{dc}}$. The thermomechanical properties of the different materials used in the ANSYS simulation are summarized in Table I.

The Y-displacement and temperature distribution profiles at $10 \mathrm{~V}_{\mathrm{dc}}$ are shown in Fig. 5(a) and (b), respectively. In Fig. 5(a), a mechanical rotation angle of approximately $0.9^{\circ}$ is obtained when a total dc voltage of $10 \mathrm{~V}$ is applied to actuators 3 and 4 . In addition, parasitic vertical out-of-plane displacement of approximately $170 \mu \mathrm{m}$ can be noted at the center of the mirror. Such out-of-plane displacement may lead to the off-center shift of the laser spot. This is due to the limited capability of the four electrothermal actuators to only actively actuate downward, but not upward as it would be needed for pure tilt motion without the off-center shift of the laser spot. Fig. 5(b) shows the temperature distribution profile of the device, where the greatest rise in temperature occurs at the biased electrothermal actuators 3 and 4 . The unbiased actuators 1 and 2 remain at room temperature while a uniform temperature of approximately $100{ }^{\circ} \mathrm{C}$ is observed for the frame and mirror plate.

\section{B. EM Actuation}

The horizontal scanning induced by EM actuation is based on the Lorentz force excitation of the MEMS mirror, which, in turn, is created by an external magnetic field and currentcarrying EM coils. Fig. 6(a) and (b) shows the 3-D and top view schematic drawing of the mirror device in the presence of magnetic field. Two layers of EM coils, each having 54 turns, are deposited and patterned on the frame. Both layers of coils, which are made of $\mathrm{Al}$, run in the same clockwise direction so that the Lorentz forces generated in both layers are the same. A pair of permanent magnets, as shown in Fig. 6(a), is arranged such that a magnetic field along the $x$-direction is formed across the device. The current direction is reversed across the scan axis due to the current forming a loop in the EM coils on the frame. This causes a change in direction of the Lorentz force across the scan axis, resulting in a torque normal to the external magnetic to be generated about the $z$-axis. To achieve continuous horizontal scanning operation, an ac current will be needed so that the Lorentz force and mechanical torque generated change direction according to the direction of the current flow. As shown in Fig. 6(b), the out-of-plane Lorentz force acting on a dc current-carrying conductor is given as

$$
\mathrm{F}=\oint_{\mathrm{L}} I \mathrm{dl} \times \mathrm{B}
$$



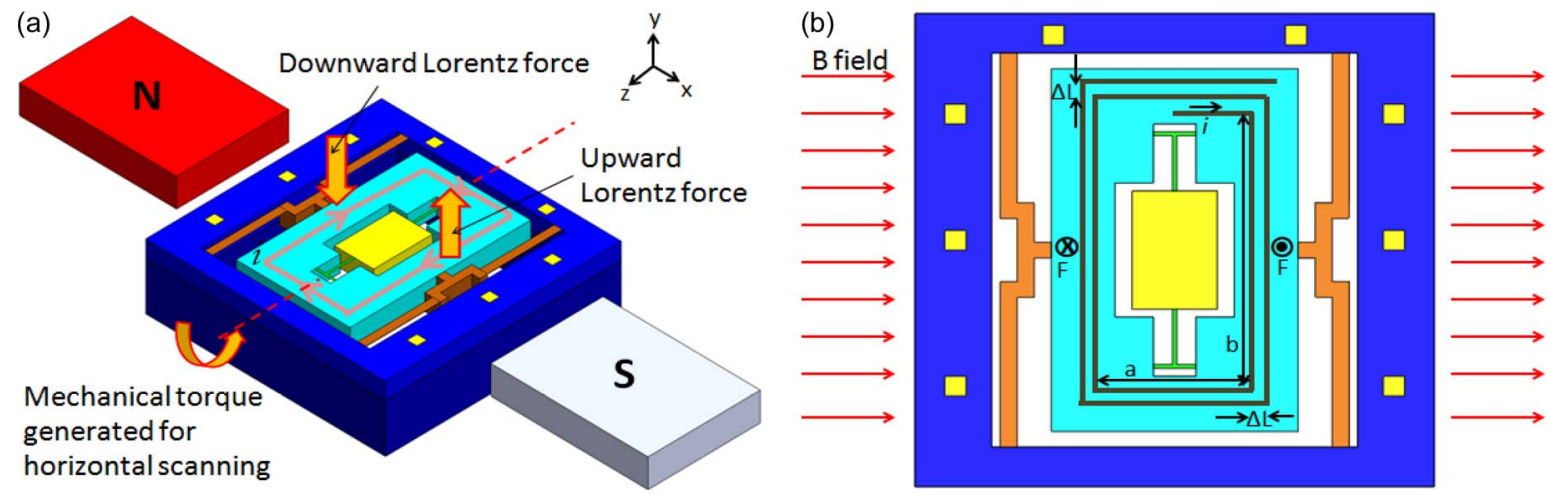

Fig. 6. (a) Schematic drawing illustrating the working principle of EM actuation and rotation about the horizontal scanning axis, i.e., $z$-axis, when a mechanical torque, in the presence of external magnetic field, is generated due to the current flow in the coil embedded in the frame. (b) Top view drawing illustrating the dimensions of the coils. Two turns of the EM coil are shown for simplicity.

(a)

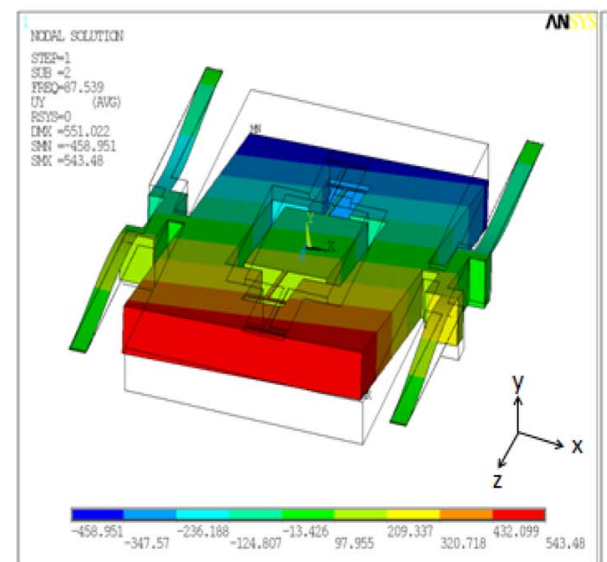

(b)

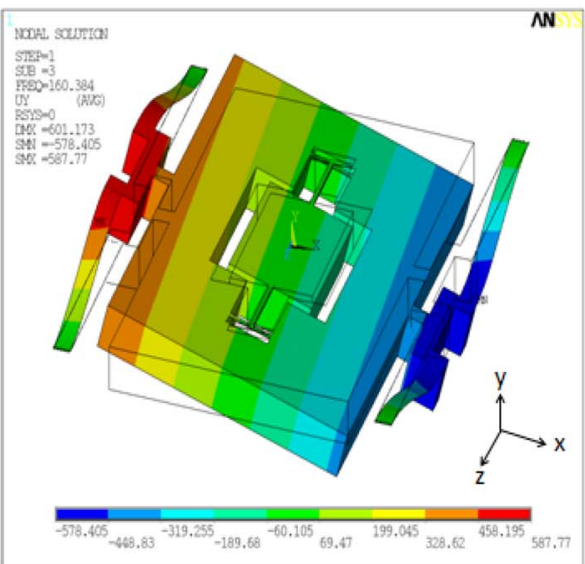

(c)

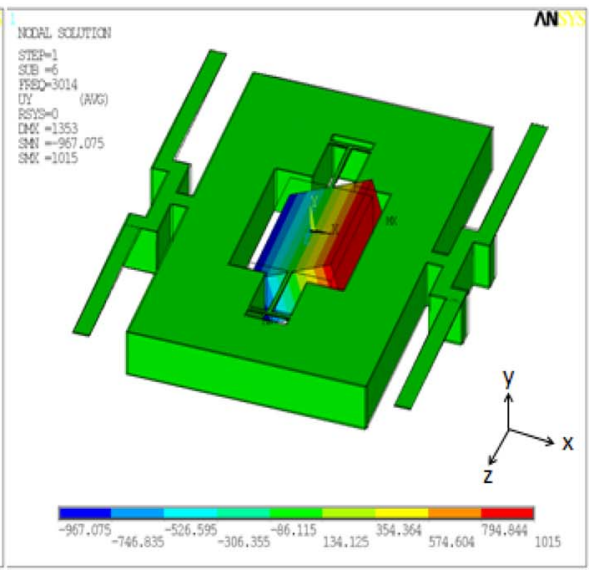

Fig. 7. Various mode shapes of the device derived from ANSYS simulation. (a) Second eigenmode at $87.5 \mathrm{~Hz}$ for vertical scanning. (b) Third eigenmode at $160.3 \mathrm{~Hz}$ for horizontal scanning. (c) Sixth eigenmode at $3014 \mathrm{~Hz}$ for horizontal scanning.

where $I$ is the current flowing in a closed circuit of length $\mathrm{L}$ and $\mathrm{B}$ is the external magnetic field. The torque generated about the $z$-axis is approximated as [39]

$$
\mathrm{T}=i \mathrm{~B} \sum_{\mathrm{m}=0}^{\mathrm{N}-1}(\mathrm{~b}+2 \mathrm{~m} \cdot \Delta \mathrm{l})(\mathrm{a}+2 \mathrm{~m} \cdot \Delta \mathrm{l})
$$

where $i$ is the current flowing in the EM coils, $\mathrm{N}$ is the number of coil turns, and $\mathrm{a}$ and $\mathrm{b}$ are the side lengths of the most inner coil turn on the short and long sides of the frame, respectively. The first term in the summation component of (3) arises from the Lorentz force generated due to the current-carrying coils that are parallel to the $z$-axis while the second term arises from the torque induced from the Lorentz force generated in all the coils. Thus, from (3), it can be deduced that a greater torque is induced when stronger magnets and larger current are used and a greater number of coil turns are fabricated on the device.

\section{Modal Analysis}

Finite-element modal analysis using ANSYS software is also made to investigate the frequency response and actuation behavior of our proposed mirror device. To decrease the computational cost, the entire model is assumed to be made up of silicon. The values of the mechanical properties for silicon material required in the simulation are summarized in Table I. Fig. 7 shows the various mode shapes of the device derived from ANSYS simulation. The second mode shape in Fig. 7(a), with a calculated modal frequency of $87.5 \mathrm{~Hz}$, corresponds to the intended purpose for vertical slow scanning by electrothermal actuation. Fig. 7(b) shows the third eigenmode at $160.3 \mathrm{~Hz}$, in which the frame and the mirror move in phase and deflect by the same amount. Slight tilts about their respective scanning axes are observed from the mode shapes in Fig. 7(a) and (b).

However, at a higher eigenfrequency of $3014 \mathrm{~Hz}$ shown in Fig. 7(c), there is negligible movement of the frame while the mirror plate oscillates along the $z$-axis. A thick $\mathrm{Si}$ substrate is intentionally left beneath the C-shaped hinge and frame so as to provide rigidity to these structures. This allows little energy to be lost due to structure deformation and more energy to be transferred through the T-shaped torsion bar to the mirror plate. Both of the derived mode shapes in Fig. 7(b) and (c) correspond to the intended purpose for horizontal fast scanning by EM actuation.

\section{Device Microfabrication}

Fig. 8 shows the CMOS-compatible microfabrication process flow of the MEMS mirror device investigated in this paper. An 8-in SOI wafer with a 3- $\mu \mathrm{m}$-thick Si device layer, $1.1-\mu \mathrm{m}$-thick buried oxide (BOX) layer, and $725-\mu \mathrm{m} \mathrm{Si}$ handle layer was used as the starting material. First, a 
(a)

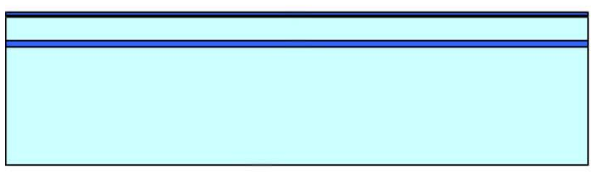

(c)

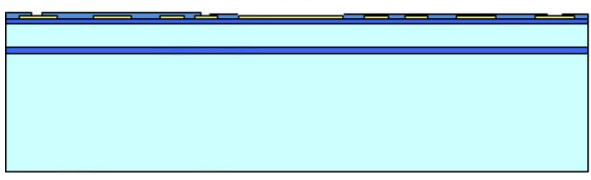

(e)

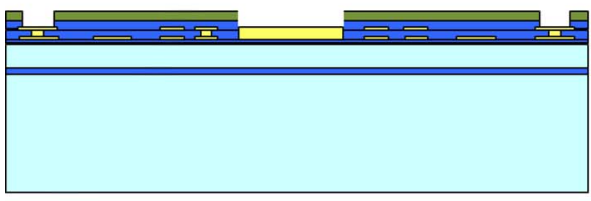

(g)

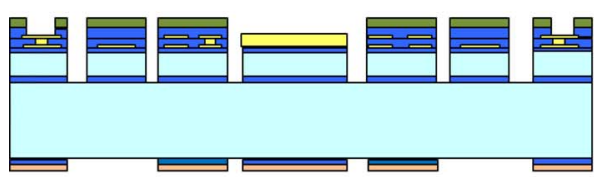

Starting material: SOI wafer $3 \mu \mathrm{m}$ Si device layer

$1.1 \mu \mathrm{m}$ BOX layer

$725 \mu \mathrm{m}$ Si handle layer (b)

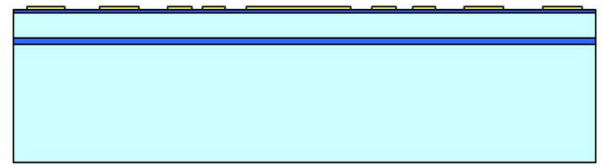

(d)

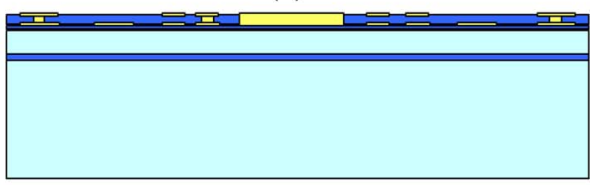

(f)

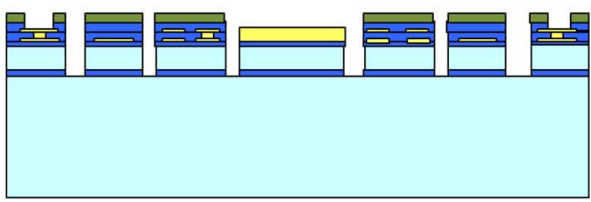

(h)
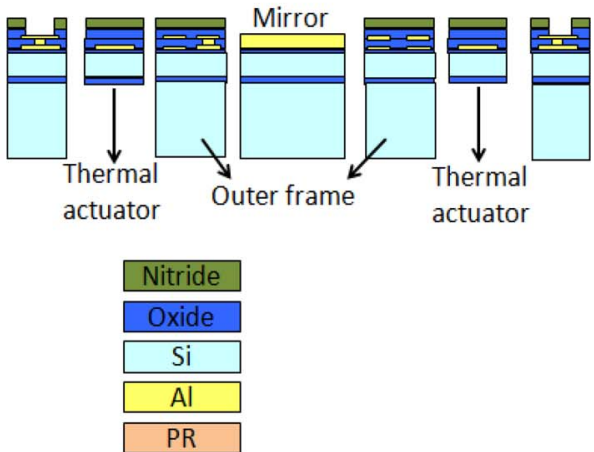

Fig. 8. Microfabrication process flow of the device.

$0.2-\mu$ m-thick thermal insulating $\mathrm{SiO}_{2}$ is deposited on the front side of the wafer by plasma-enhanced chemical vapor deposition (PECVD) [see Fig. 8(a)]. This is followed by physical vapor deposition, patterning, and reactive ion etching (RIE) of $2-\mu \mathrm{m}$-thick $\mathrm{Al}$ at the electrothermal actuator winding, EM coil, bond pad, and mirror regions using $\mathrm{Cl}_{2}$ and $\mathrm{Ar}$ gases [see Fig. 8(b)]. A $0.5-\mu$ m-thick $\mathrm{SiO}_{2}$, which serves as the thermal and the electrical insulation for the electrothermal windings and EM coil regions, respectively, is next deposited by PECVD. Bond pad openings are then formed by RIE of $\mathrm{SiO}_{2}$ using $\mathrm{CHF}_{3}$ [see Fig. 8(c)]. A second layer of $\mathrm{Al}$ is again deposited, patterned, and etched, except that the processes happen only at the EM coil, mirror, and bond pad regions [see Fig. 8(d)]. PECVD $\mathrm{SiO}_{2}$ and $\mathrm{Si}_{3} \mathrm{~N}_{4}$, each of $0.5 \mu \mathrm{m}$ thick, are then deposited as passivating layers. Al remains as the top layer in the mirror region so as to enhance the reflectivity of the mirror surface. This is followed closely by $\mathrm{RIE}$ of $\mathrm{SiO}_{2}$ and $\mathrm{Si}_{3} \mathrm{~N}_{4}$ for contact hole opening [see Fig. 8(e)]. The front-side features of the microstructures such as the mirror, electrothermal actuators, and T-shaped torsion bar are then defined through RIE of $\mathrm{Si}_{3} \mathrm{~N}_{4}$, $\mathrm{SiO}_{2}$, Si device, and BOX layers using $\mathrm{CF}_{4}$ (for $\mathrm{Si}_{3} \mathrm{~N}_{4}$ ), $\mathrm{CHF}_{3}$ (for $\mathrm{SiO}_{2}$ ), and $\mathrm{SF}_{6}$ (for $\mathrm{Si}$ ), respectively [see Fig. 8(f)].

After all the front-side wafer processes are finished, the $\mathrm{Si}$ handle layer of the SOI wafer is reduced to approximately $450 \mu \mathrm{m}$ by undergoing backside grinding and polishing. Next, a thin layer of 2- $\mu \mathrm{m}$ PECVD $\mathrm{SiO}_{2}$ is deposited and patterned at the backside of the wafer. The photoresist used to pattern the oxide layer remains behind after the oxide etch so that both the photoresist and the oxide can function as the hard mask for backside Si deep reactive ion etch (DRIE) during the subsequent step [see Fig. 8(g)]. Prior to the DRIE process, the wafer is first diced to the single mirror chip level $(6 \mathrm{~mm} \times 6 \mathrm{~mm})$ as the mirror device becomes very fragile when released and any impact either in a wet process or due to handling can break the microstructures easily. The diced mirror chips are then placed on a support wafer and immobilized using adhesive thermal tape, which is compatible with Si DRIE process. The DRIE process is conducted in a time-controlled manner as the process does not stop effectively on the BOX layer. $400 \mu \mathrm{m}$ of silicon handle layer is first etched away, with the remaining $50 \mu \mathrm{m}$ of silicon gradually etched in many etch steps, each of 5-min duration. After each etch step, the wafer is taken out, and the backside of the wafer is checked under the optical microscope so as to determine whether the entire Si handle layer has been fully etched away. A 450- $\mu$ m-thick Si substrate is left beneath the mirror to maintain the rigidity and flexibility [see Fig. 8(h)].

Fig. 9(a) shows a completed MEMS mirror device, placed beside a Singapore five-cent coin. As shown in Fig. 9(b), the device is then bonded onto a dual inline package (DIP), with a spacer chip placed beneath the device. The spacer chip elevates the device from the base of the DIP, hence avoiding hindrance to the mirror plate movement during actuation. The $\mathrm{Al}$ bond pads are connected by gold bond wires to the metal pins of the DIP. Fig. 10 shows the optical micrographs of various parts of the 


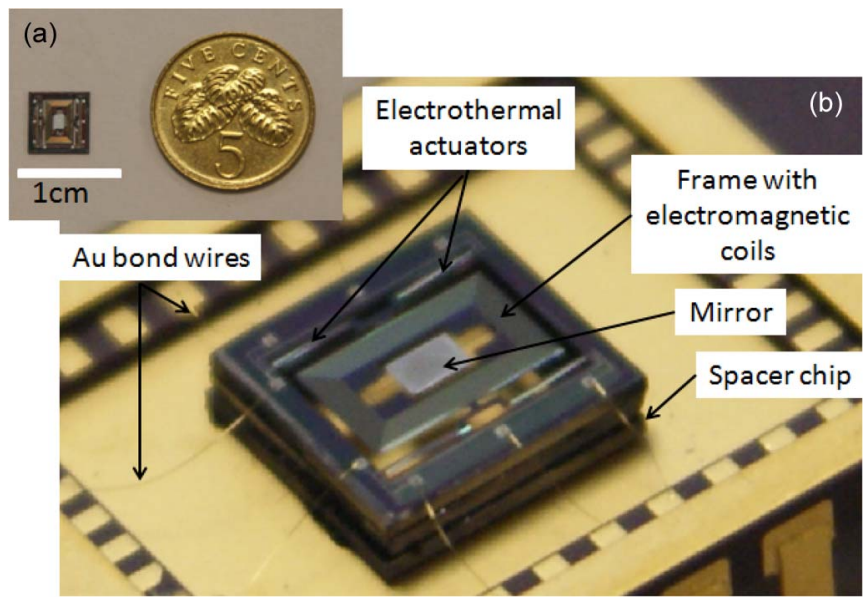

Fig. 9. Photographs showing (a) an unpackaged 2-D MEMS mirror placed beside a Singapore five-cent coin. (b) Close-up view of the device in a DIP and the bond pads connected to the pins of the package via gold bond wires.

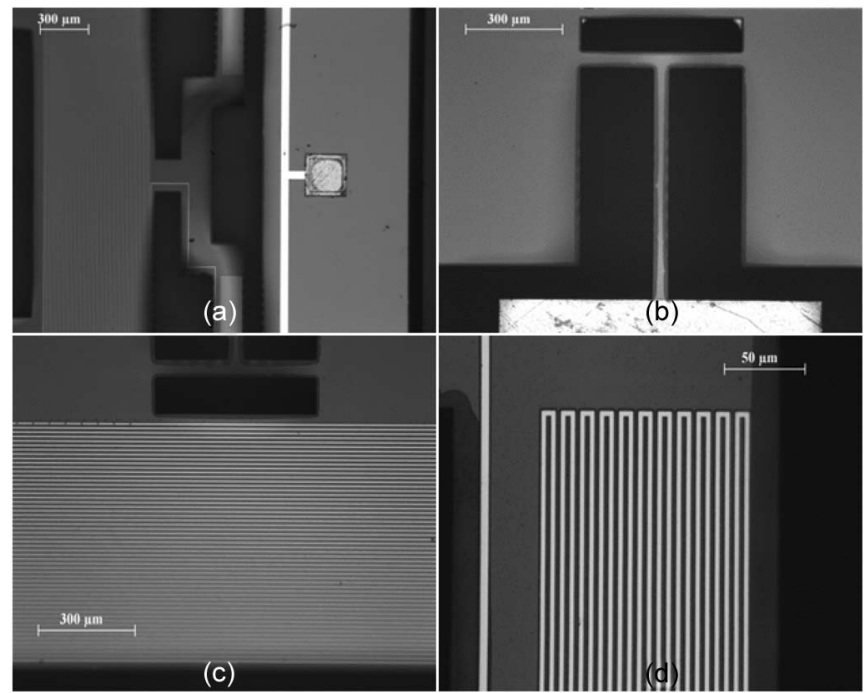

Fig. 10. Optical micrographs showing the (a) C-shaped hinge connecting the thermal actuators to the frame, (b) T-shaped torsion bar, (c) Al EM coils embedded in the frame, and (d) Al windings of the electrothermal actuator.

mirror device. Fig. 10(a) shows the $\mathrm{C}$-shaped hinge connecting the electrothermal actuators to the frame, while Fig. 10(b) shows the T-shaped torsion bar of width $50 \mu \mathrm{m}$ connecting the mirror plate to the frame. Fig. 10(c) and (d) shows the EM Al coils embedded in the frame and Al windings of the electrothermal actuator, respectively. There are two layers of Al EM coils, with each layer having 54 coils. Each electrothermal actuator has $22 \mathrm{Al}$ windings of width $3 \mu \mathrm{m}$. Details of the structural parameters for the fabricated device are summarized in Table II.

\section{EXPERIMENTAL SETUP}

The schematic drawing of the experimental setup is illustrated in Fig. 11. The optical measurement setup consists of a red laser source with an angle-adjustable tripod, a dc voltage supply, and a function generator for dc and ac characterization, respectively. Incident light from the light source gets reflected by the mirror and propagates toward the screen with an optical deflection angle (ODA) of $2 \theta$, where $\theta$ denotes the mechanical rotation angle. The screen is placed and fixed perpendicularly to
TABLE II

Structural Parameters of the Fabricated DEVICE SHOWN IN Fig. 10

\begin{tabular}{ll}
\hline \hline Structural parameters & Values \\
\hline Die size & $6 \mathrm{~mm} \times 6 \mathrm{~mm}$ \\
Mirror size $(1 \times \mathrm{w} \times \mathrm{t})$ & $1.5 \mathrm{~mm} \times 1 \mathrm{~mm} \times 0.45 \mathrm{~mm}$ \\
T-shaped torsion bar $(\mathrm{w} \times \mathrm{t})$ & $50 \mu \mathrm{m} \times 5 \mu \mathrm{m}$ \\
Electrothermal actuator $(1 \times \mathrm{w} \times \mathrm{t})$ & $1850 \mu \mathrm{m} \times 200 \mu \mathrm{m} \times 7 \mu \mathrm{m}$ \\
Electrothermal actuator winding & $1800 \mu \mathrm{m} \times 3 \mu \mathrm{m} \times 2 \mu \mathrm{m}$ \\
$(1 \times \mathrm{w} \times \mathrm{t})$ & 22 \\
No. of windings & $3 \mu \mathrm{m} \times 2 \mu \mathrm{m}$ \\
Electromagnetic coil $(\mathrm{w} \times \mathrm{t})$ & 54 \\
No. of coils in each layer &
\end{tabular}

$$
\theta=\frac{\tan ^{-1}(\mathrm{~L} / \mathrm{H})}{2}
$$

Red light from $\mathrm{He} / \mathrm{Ne}$ laser

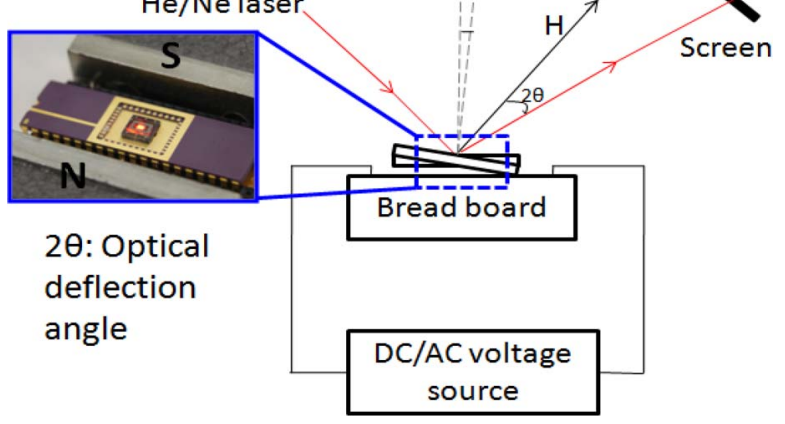

Fig. 11. Experimental setup for the optical characterization of device. Inset shows the packaged device placed in between the magnets, with red laser light impinging on the mirror surface.

the reflected light when the device is initially unbiased. When the actuator is driven in ac mode, a mechanical rotation angle of $\pm \theta$ is introduced to the mirror plate. The resulted reflected light will be deviated from the original light path with an angle of $\pm 2 \theta$, and the light spot on the screen will be shifted by a distance $\pm \mathrm{L}$. The value of $\theta$ can then be derived from the measured $\mathrm{L}$ and known distance $\mathrm{H}$, where $\mathrm{H}$ is the distance of the screen from the mirror. The inset of Fig. 11 shows the packaged device placed in between the magnetic field of a pair of Alcomax III magnets, with red laser light impinging on the mirror surface. The magnetic field strength at the center of the pair of magnets is measured by a Gauss meter and is approximately $0.15 \mathrm{~T}$.

\section{RESUltS AND Discussion}

Several experiments have been carried out to characterize both the electrothermal and EM actuators in terms of static, dynamic responses, and 2-D scanning patterns.

\section{A. Static Characterization}

The $I-V$ curves of the electrothermal windings and the EM coils are shown in Fig. 12. An Agilent b1500a semiconductor device analyzer is used to bias and obtain the $I-V$ characteristic of the device. Both electrothermal actuators 1 and 2 are connected electrically in series for both static and dynamic characterizations. This also applies to electrothermal actuators 3 and 4. As observed from Fig. 12, the $I-V$ curves for the two sets of electrothermal actuators are identical, with both having 


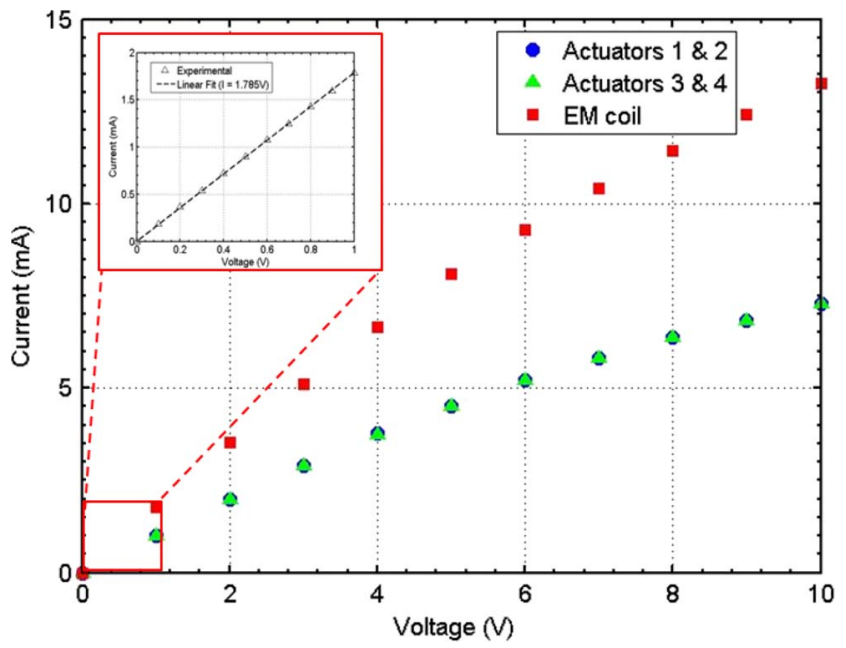

Fig. 12. $I-V$ curves obtained for the EM coil, with actuators 1 and 2 connected in series and actuators 3 and 4 connected in series. The inset shows a detailed sweep of the EM coil within the $1-\mathrm{V}_{\mathrm{dc}}$ range, obeying a linear fit of $I(m A)=1.8 \mathrm{~V}(\mathrm{~V})$.
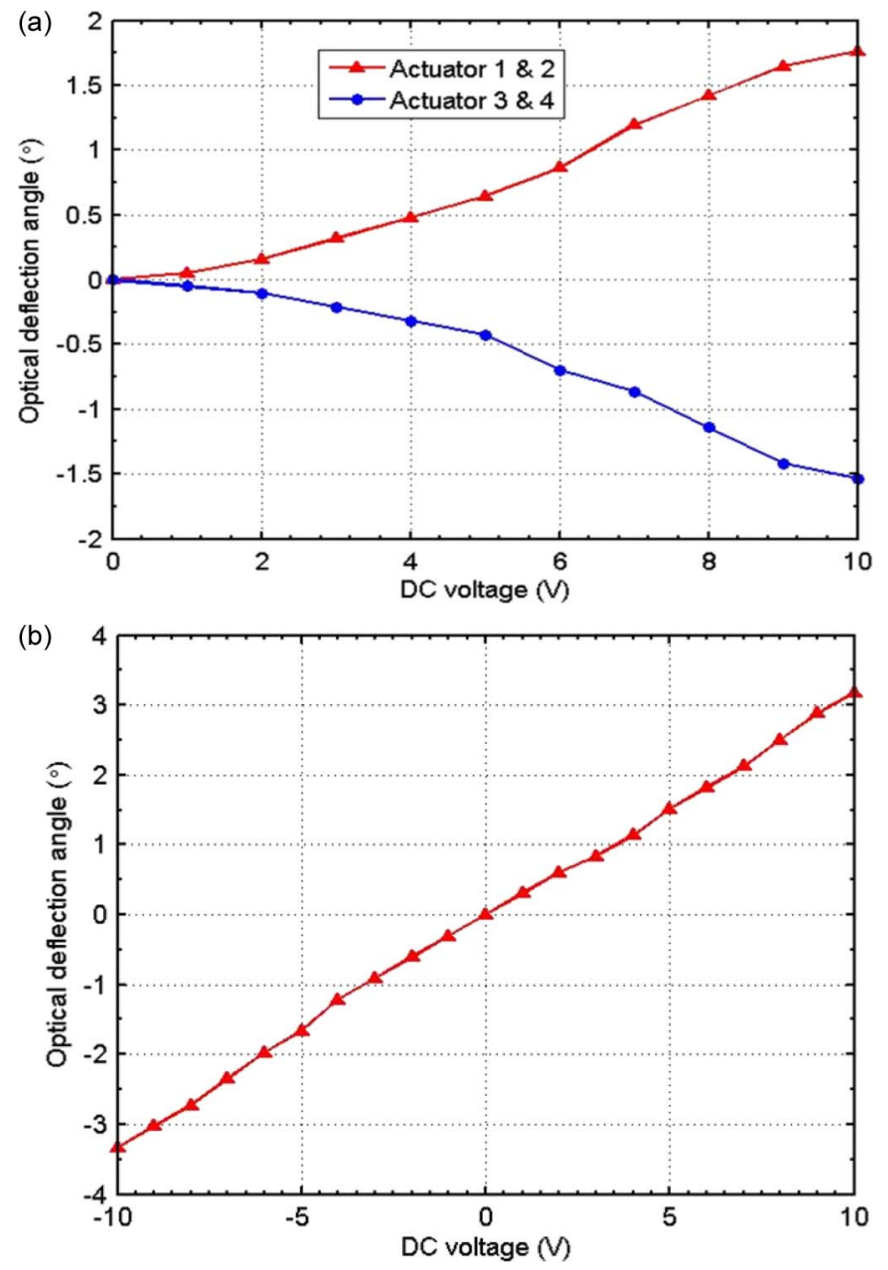

Fig. 13. DC response for (a) electrothermal actuation and (b) EM actuation.

a thermal power consumption of approximately $73 \mathrm{~mW}$ at $10 \mathrm{~V}_{\mathrm{dc}}$. In the case of EM actuation, the magnitude of the current flow plays a more pivotal role in the actuation performance compared to the thermal power consumption for electrothermal actuation. A current of $13.3 \mathrm{~mA}$ is obtained when $10 \mathrm{~V}_{\mathrm{dc}}$
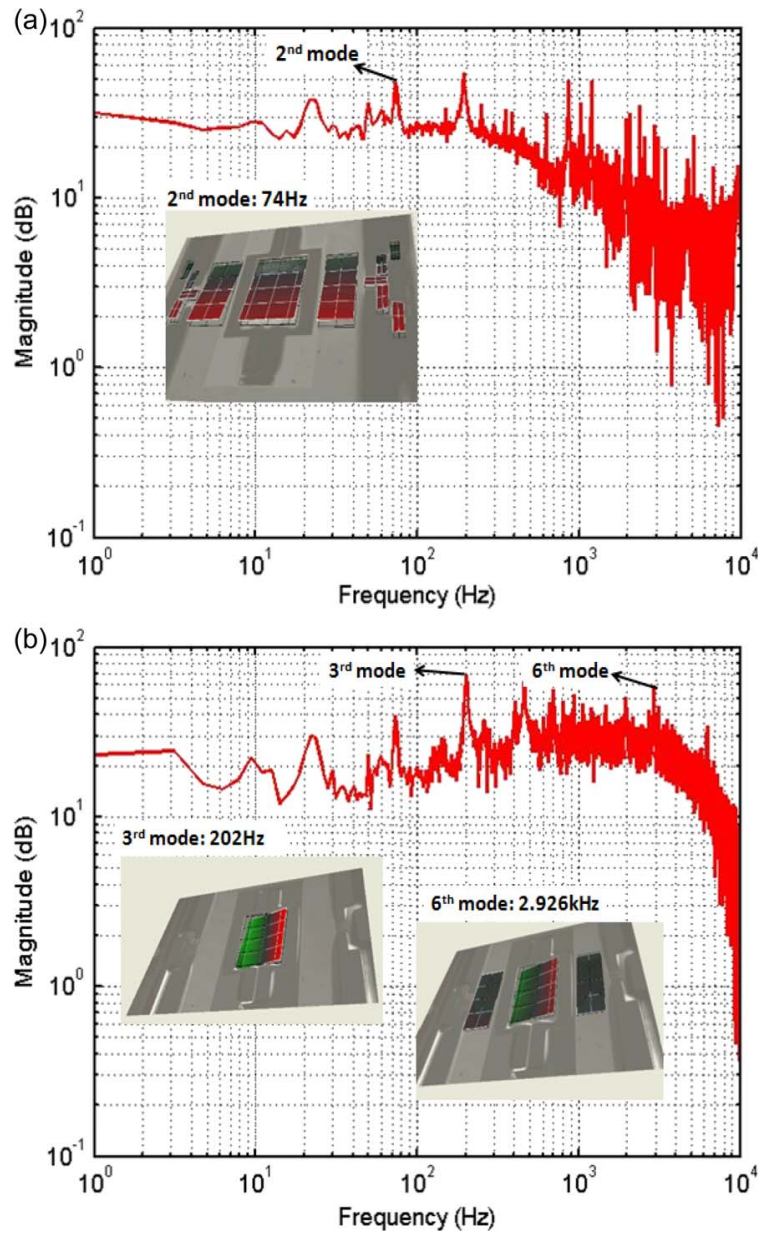

Fig. 14. Bode plots illustrating the frequency response for (a) electrothermal actuation where actuators 1 and 2 are biased in series and (b) EM actuation.

is applied to the EM coils. This is equivalent to a power consumption of $133 \mathrm{~mW}$ at $10 \mathrm{~V}_{\mathrm{dc}}$ for EM actuation. The inset of Fig. 12 shows a detailed sweep of the EM coil within the $1-\mathrm{V}_{\mathrm{dc}}$ range. In this bias range, the EM coil behaves like an ohmic conductor, obeying the linear fit $I(m A)=1.8 \mathrm{~V}(\mathrm{~V})$. The $1-\mathrm{V}_{\mathrm{dc}}$ bias range will be of interest during $\mathrm{EM}$ ac actuation, which will be discussed later in the section.

Fig. 13(a) and (b) show the static dc response for the electrothermal and EM actuations, respectively.

The experiment is carried out using the optical measurement setup described earlier in Section IV. The static rotation measurement is taken by applying a dc voltage to only one set of serially connected electrothermal actuators, while leaving the other set unbiased. As shown in Fig. 13(a), when the electrothermal actuators 1 and 2 are biased at $10 \mathrm{~V}_{\mathrm{dc}}$, the actuators bend down and cause the frame and mirror plate to rotate about the $x$-axis. This introduces a positive static ODA of $1.8^{\circ}$. Similarly, when electrothermal actuators 3 and 4 are biased at $10 \mathrm{~V}_{\mathrm{dc}}$, the frame and mirror rotate in the opposite direction about the same axis, introducing a negative static ODA of $1.5^{\circ}$. The de static performance for actuators 1 and 2 is better compared to that for actuators 3 and 4 . This small discrepancy may be due to lithographic and fabrication inaccuracies. Fig. 13(b) shows the dc response for the EM actuation, where positive and negative dc voltages are applied to the EM coils. When a positive dc bias is applied, the current 

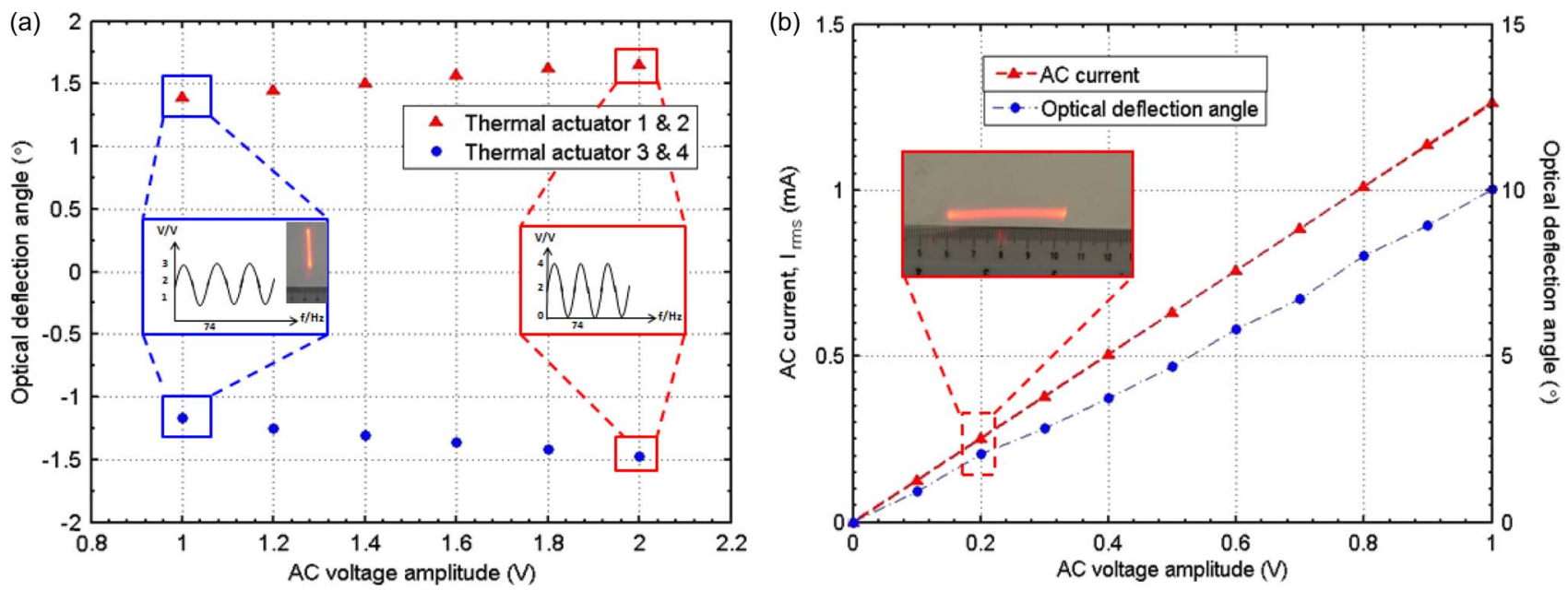

Fig. 15. AC response for (a) electrothermal actuation at $74 \mathrm{~Hz}$ for two different cases of biasing configurations and (b) EM actuation at $202 \mathrm{~Hz}$, with inset showing an example of a horizontal scanning trajectory line produced during EM actuation.

flows in a clockwise direction around the coils, and the frame experiences a mechanical torque in the presence of a magnetic field. At $10 \mathrm{~V}_{\mathrm{dc}}$, the mirror rotates about the $z$-axis, causing an ODA of $+3.1^{\circ}$. In the case where negative dc bias is applied, the current flowing in the coil changes direction, i.e., anticlockwise direction. The mirror rotates in the opposite direction about the same axis, introducing an ODA of $-3.3^{\circ}$.

\section{B. Dynamic Characterization}

Fig. 14(a) and (b) shows the Bode plots illustrating the frequency responses of electrothermal and EM actuations, respectively. A Polytec MSA-500 laser Doppler vibrometer (LDV) is used to obtain both the frequency responses of the device, with the measurement point being located at the top corner of the frame. A $1-\mathrm{V}_{\mathrm{ac}}$ sinusoidal excitation signal is used to bias the device while the LDV sends a laser beam to the point of interest and measures the Doppler shift of the returning beam. Fig. 14(a) shows the Bode plot obtained for electrothermal actuation, where electrothermal actuators 1 and 2 were biased with the excitation signal. The inset of Fig. 14(a) shows the second mode shape of the mirror obtained from the vibration analysis in the LDV. This mode shape corresponds to that required for vertical scanning, and it occurs at $74 \mathrm{~Hz}$, which is pretty close to the modal frequency of $87.5 \mathrm{~Hz}$ obtained from the FEM simulation. The same procedure is made for EM actuation, and a Bode plot, as shown in Fig. 14(b), is obtained. As shown in the inset of Fig. 14(b), the mode shapes of the mirror for the third and sixth modes correspond to that required for horizontal scanning. The third mode occurs at $202 \mathrm{~Hz}$, while the modal frequency obtained from simulation is $160.3 \mathrm{~Hz}$. Similarly, the sixth mode occurs at a higher frequency of $2926 \mathrm{~Hz}$ while the simulated modal frequency is $3014 \mathrm{~Hz}$. The disparity between the experimental and simulated frequencies is due to the consideration of the entire model being made of silicon only during the ANSYS simulation while, in reality, the device is made of several layers of thin film material in addition to single crystalline silicon. The $3-\mathrm{dB}$ cutoff frequency for electrothermal actuation in Fig. 14(a) is about $3 \mathrm{~Hz}$. This slow thermal response is caused by the large thermal resistances introduced by the windings of the electrothermal actuator.
TABLE III

COMPARISON OF FOM FOR DIFFERENT EM SCANNER DESIGNS

\begin{tabular}{|c|c|c|}
\hline Ref & Unique feature & FOM \\
\hline This work & Hybrid actuated scanner & 3.20 \\
\hline Urey et al. [38] & $\begin{array}{l}\text { FR4 based scanner; Low } \\
\text { cost }\end{array}$ & 1.17 \\
\hline Yalcinkaya et al. [39] & State-of-the-art scanner & 12.09 \\
\hline Yalcinkaya et al. [42] & $\begin{array}{l}\text { Polymer based barcode } \\
\text { scanner; }\end{array}$ & 0.43 \\
\hline Yalcinkaya et al. [43] & $\begin{array}{l}\text { Magnetostatic NiFe } \\
\text { plated scanner }\end{array}$ & 0.48 \\
\hline Tang et al. [44] & $\begin{array}{l}\text { Torque enhanced } \mathrm{Ni} \\
\text { plated scanner }\end{array}$ & 0.38 \\
\hline
\end{tabular}

Fig. 15(a) and (b) shows the ac response of the device for the electrothermal and the EM actuation, respectively. Both the electrothermal and EM actuators are biased individually with a sinusoidal ac voltage at their respective resonant frequencies while observing the length of the scanning trajectories produced at varying ac voltage amplitude. Two Agilent 33120 A function waveform generators are used to bias and excite the device for the electrothermal and the EM actuation, respectively. Fig. 15(a) shows the ac response for electrothermal actuation at $74 \mathrm{~Hz}$ for two different bias configurations. An ac voltage, on top of a $2-\mathrm{V}_{\mathrm{dc}}$ offset bias, was applied to the two sets of electrothermal actuators separately. The insets of Fig. 15(a) show examples of the voltage bias waveforms at $1 \mathrm{~V}_{\mathrm{ac}}$ and $2 \mathrm{~V}_{\mathrm{ac}}$. In the case where electrothermal actuators 1 and 2 are biased, the ODA obtained at $2 \mathrm{~V}_{\mathrm{ac}}$ with a $2-\mathrm{V}_{\mathrm{dc}}$ offset is $+1.6^{\circ}$ compared to $+1.4^{\circ}$ at $1 \mathrm{~V}_{\mathrm{ac}}$ with a $2-\mathrm{V}_{\mathrm{dc}}$ offset. This is because of a larger peak-to-peak voltage difference for the former compared to the latter biasing condition, hence resulting in larger difference in the heating effect. In the case where electrothermal actuators 3 and 4 are biased, the ODA obtained at $2 \mathrm{~V}_{\mathrm{ac}}$ with a $2-\mathrm{V}_{\mathrm{dc}}$ offset is $-1.5^{\circ}$. Hence, from these results, we can potentially obtain an approximate optical scan range of $\pm 1.5^{\circ}$ at $2 \mathrm{~V}_{\mathrm{ac}}$ with a $2-\mathrm{V}_{\mathrm{dc}}$ offset when we bias the two sets of thermal actuators at $180^{\circ}$ out of phase with each other. Such a biasing configuration would result in approximately $12 \mathrm{~mW}$ of thermal power being consumed by both sets of electrothermal actuators. In addition, due to the compliance of the function generator, the biasing condition for the electrothermal actuators 


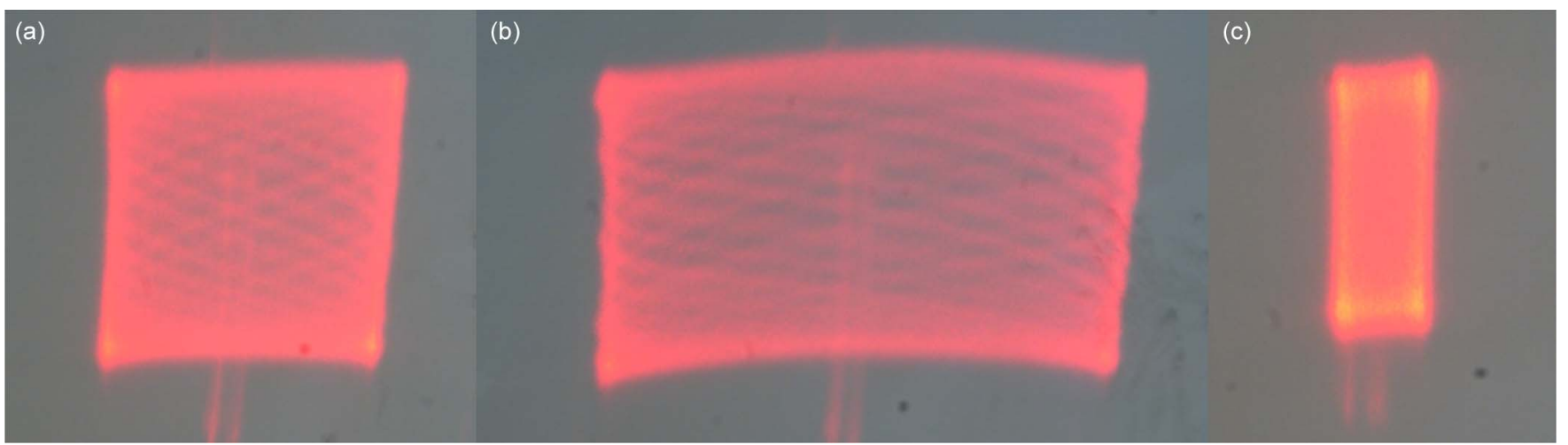

Fig. 16. Various Lissajous patterns generated from different combinations of electrothermal and EM biasing configurations. Electrothermal actuators 1 and 2 at $2 \mathrm{~V}_{\mathrm{dc}}, 2 \mathrm{~V}_{\mathrm{ac}}$, and $74 \mathrm{~Hz}$ are responsible for the horizontal scanning in all three patterns while the biasing conditions for the vertical scanning are (a) $0.1 \mathrm{~V}_{\mathrm{ac}}$ or $0.126 \mathrm{~mA}$ and $202 \mathrm{~Hz}$, (b) $0.2 \mathrm{~V}_{\mathrm{ac}}$ or $0.252 \mathrm{~mA}$ and $202 \mathrm{~Hz}$, and (c) $2 \mathrm{~V}_{\mathrm{ac}}$ or $2.5 \mathrm{~mA}$ and $2926 \mathrm{~Hz}$, respectively.

is limited to $2 \mathrm{~V}_{\mathrm{ac}}$ with a $2-\mathrm{V}_{\mathrm{dc}}$ offset. The red and blue curves in Fig. 15(b) show the root-mean-square (rms) values of the current flowing in the EM coil for various ac voltages and the ac response for EM actuation at $202 \mathrm{~Hz}$, respectively. At a $1-\mathrm{V}_{\mathrm{ac}}$ bias, an rms current value of $1.26 \mathrm{~mA}$ is derived, while a dynamic ODA of $\pm 10^{\circ}$ is obtained from the optical experiment. This dynamic ODA obtained is significantly larger when compared to the static ODA of $0.3^{\circ}$ obtained at $1 \mathrm{~V}_{\mathrm{dc}}$ during static actuation. This phenomenon is due to the mirror attaining mechanical resonance from the ac electrical excitation, resulting in maximum energy transfer from the ac electrical signal to the vibrating mechanical structures. In addition, straight vertical and horizontal scanning trajectories are observed in the insets of Fig. 15(a) and (b), respectively. Hence, the tilting mode shapes previously observed from the simulation in Fig. 7(a) and (b) contribute minimum effect to both the vertical and horizontal scanning trajectories, respectively.

Table III compares the published EM actuated MEMS mirror performances according to the figure of merit (FOM), which is being used as a metric to compare the relative scanning efficiencies

$$
F O M=\frac{\theta_{o p t} D f}{I}
$$

where $\theta_{\text {opt }}$ is the total optical scan angle (in degrees), $D$ is the mirror size along the scan axis (in millimeters), $f$ is the resonant frequency (in kilohertz), and $I$ is the drive current (in milliamperes). The FOM obtained during EM actuation for our work $\left(\theta_{\text {opt }}=20^{\circ}, D=1 \mathrm{~mm}, f=0.202 \mathrm{kHz}\right.$, and $I=$ $1.26 \mathrm{~mA}$ ) is better than most of the EM scanners reported in recent years. This may be attributed to the large number of EM coils fabricated, resulting in extremely low driving current. To the best of our knowledge, our proposed device has one of the lowest operation voltage and current among most of the MEMS mirrors driven by EM actuation. For example, the microscanners developed by Urey et al. in [38] and Yalcinkaya et al. in [42] require approximately rms drive currents of 10 and $16 \mathrm{~mA}$ to reach a total optical scan angle of $20^{\circ}$ and $15^{\circ}$, respectively. These scanners' performances are less efficient than our obtained ODA of $\pm 10^{\circ}$ at $1 \mathrm{~V}_{\mathrm{ac}}$ and $1.26 \mathrm{~mA}$ for EM actuation. However, our device's performance remains pale in comparison to the state-of-the-art EM MEMS mirror developed by Yalcinkaya et al. for high-resolution retinal scanning display [39].

Various 2-D Lissajous patterns generated from different combinations of electrothermal and EM biasing configurations are shown in Fig. 16. The vertical scanning in Fig. 16(a)-(c) is driven by biasing electrothermal actuators 1 and 2 at $74 \mathrm{~Hz}$ and $2 \mathrm{~V}_{\mathrm{ac}}$ with a $2-\mathrm{V}_{\mathrm{dc}}$ offset. The horizontal scanning occurs by biasing the EM coils at the resonant frequencies of either 202 or $2926 \mathrm{~Hz}$. The horizontal trajectory length becomes longer as the bias applied to the EM coil increases. Minimum coupling is observed between the vertical and the horizontal scanning as the horizontal and vertical trajectories, shown in the insets of Fig. 15(a) and (b), respectively, forming straight lines instead of elliptical loops. The distortion of the scanning image seen in Fig. 16(b) is caused mainly by the inclined laser beam incidence on the mirror and the tilted screen against the optical axis. Such scanning image can be easily corrected using the properly designed projection optics. A video clip illustrating this phenomenon and the Lissajous scan pattern is available for download at http://ieeexplore.ieee.org. Fig. 16(c) illustrates the raster scanning pattern obtained by biasing the EM coil at $2 \mathrm{~V}_{\mathrm{ac}}$ and $2926 \mathrm{~Hz}$. Unfortunately, no significant mechanical amplification experimental result is observed as the horizontal trajectory length obtained in Fig. 16(c) is relatively smaller $\left( \pm 1.1^{\circ}\right.$ and $2.5 \mathrm{~mA})$ compared to that in Fig. 16(b) $\left( \pm 2^{\circ}\right.$ and $\left.0.25 \mathrm{~mA}\right)$. This might be due to the thick bulk $\mathrm{Si}$ substrate underneath the mirror and the air damping force being larger at higher frequency, causing the actuation motion of the mirror plate to be heavily damped at $2926 \mathrm{~Hz}$ compared to $202 \mathrm{~Hz}$. Nevertheless, we are able to demonstrate the higher resonant mode $(2.9 \mathrm{kHz})$ and its corresponding 2-D scanning pattern in Fig. 16(c). This illustrates the feasibility of using the hybrid-actuated single mirror approach and leveraging the concept of mechanical amplification mechanism for 2-D scanning purposes.

The optimization of the resonant frequency to higher value and characterization of our devices in vacuum conditions are the next steps to further improve the scan angle at higher frequency and performance of our proposed scanning mirror device. The thickness of the bulk Si beneath the mirror plate may be further reduced so as to decrease the mass inertia. A reinforcement rib, instead of the entire bulk Si substrate, may be patterned and fabricated beneath the mirror surface so as to 
overcome the issue of dynamic deformation of a thinner mirror plate during high-frequency scan.

\section{CONCLUSION}

A novel proof-of-concept CMOS-compatible MEMS scanning mirror based on hybrid actuation mechanisms has been proposed and verified for 2-D raster scanning application. Both electrothermal and EM actuations have been integrated in the same device for slow and fast scanning purposes, respectively. This makes our design essentially different from most of the 2-D scanning mirror designs already reported in the literature where the same actuation mechanism is often used to drive both the orthogonal scanning axes of the mirror devices. We have confirmed the various mode shapes and demonstrated that 2-D scanning can be achieved by a single mirror approach using our design of mechanical amplification mechanism. The added advantage of a CMOS-compatible fabrication process allows for ease of monolithic integration, hence adding new functionality to integrated electronics. An optical scan angle of $\pm 1.5^{\circ}$ for the $74-\mathrm{Hz}$ vertical scan at $12 \mathrm{~mW}$ for electrothermal actuation and that of $\pm 10^{\circ}$ for the horizontal scan frequency of $202 \mathrm{~Hz}$ at $1.26 \mathrm{~mA}$ and $1 \mathrm{~V}_{\mathrm{ac}}$ for EM actuation are reported. The outstanding optical performance in terms of low operating voltage and above-par FOM obtained by the device during EM actuation is among the best reported in the literature. Our unique design of using both electrothermal and EM actuation mechanisms for 2-D raster scanning is the first demonstration of such hybrid-driven CMOS-compatible MEMS mirror, with its low power consumption suitable for mobile applications powered by batteries with limited capacity.

\section{REFERENCES}

[1] H. Liu, C. J. Tay, C. Quan, T. Kobayashi, and C. Lee, "Piezoelectric MEMS energy harvester for low-frequency vibrations with wideband operation range and steadily increased output power," J. Microelectromech. Syst., vol. 20, no. 5, pp. 1131-1142, Oct. 2011.

[2] N. Wang, J. M.-L. Tsai, F.-L. Hsiao, B. W. Soon, D.-L. Kwong, M. Palaniapan, and C. Lee, "Experimental investigation of a cavity-mode resonator using a micromachined two-dimensional silicon phononic crystal in a square lattice," IEEE Electron Device Lett., vol. 32, no. 6, pp. 821823, Jun. 2011.

[3] Y. Qian, L. Lou, M. J. Tsai, and C. Lee, "A dual-silicon-nanowires based U-shape nanoelectromechanical switch with low pull-in voltage," Appl. Phys. Lett., vol. 100, no. 11, pp. 113102-1-113102-3, Mar. 2012.

[4] J. Xie, R. Agarwal, Y. Liu, J. M.-L. Tsai, N. Ranganathan, and J. Singh, "Compact electrode design for an in-plane accelerometer on SOI with refilled isolation trench," J. Micromech. Microeng., vol. 21, no. 9, p. 095005 , Sep. 2011.

[5] L. Lou, S. Zhang, W.-T. Park, J. M.-L. Tsai, D.-L. Kwong, and C. Lee, "Optimization of NEMS pressure sensors with multilayered diaphragm using silicon nanowires as piezoresistive sensing elements," J. Micromech. Microeng., vol. 22, no. 5, p. 055012, Apr. 2012.

[6] K. H. Koh, C. Lee, and T. Kobayashi, "A piezoelectric-driven threedimensional MEMS VOA using attenuation mechanism with combination of rotational and translational effects," J. Microelectromech. Syst., vol. 19, no. 6, pp. 1370-1379, Dec. 2010.

[7] C. Lee, F.-L. Hsiao, T. Kobayashi, K. H. Koh, P. V. Ramana, W. Xiang, B. Yang, C. W. Tan, and D. Pinjala, "A 1-V operated MEMS variable optical attenuator using piezoelectric PZT thin-film actuators," IEEE J. Sel. Topics Quantum Electron., vol. 15, pp. 1529-1536, Sep./Oct. 2009.

[8] C. Lee and J. A. Yeh, "Development and evolution of MOEMS technology in variable optical attenuators," J. Micro/Nanolith. MEMS MOEMS, vol. 7, no. 2, pp. 021003-1-021003-16, Jul. 2008.

[9] J. A. Yeh, S.-S. Jiang, and C. Lee, "MOEMS variable optical attenuators using rotary comb drive actuators," IEEE Photon. Technol. Lett., vol. 18, no. 10 , pp. 1170-1172, May 2006.
[10] M. I. Lapsley, S.-C. S. Lin, X. Mao, and T. J. Huang, "An in-plane, variable optical attenuator using a fluid-based tunable reflective interface," Appl. Phys. Lett., vol. 95, no. 8, pp. 083507-1-083507-3, Aug. 2009.

[11] M. C. Wu, O. Solgaard, and J. E. Ford, "Optical MEMS for lightwave communication," J. Lightw. Technol., vol. 24, no. 12, pp. 4433-4454, Dec. 2006.

[12] W. Noell, P. A. Clerc, L. Dellmann, B. Guldimann, H. P. Herzig, O. Manzardo, C. R. Marxer, K. J. Weible, R. Dandliker, and N. de Rooij, "Applications of SOI-based optical MEMS," IEEE J. Sel. Topics Quantum Electron., vol. 8, no. 1, pp. 148-154, Jan./Feb. 2002.

[13] T. Bifano, "Adaptive imaging MEMS deformable mirrors," Nature Photon., vol. 5, no. 1, pp. 21-23, Jan. 2011.

[14] D. Graham-Rowe, "Projectors get personal," Nature Photon., vol. 1, pp. 677-679, Dec. 2007

[15] K. Aljasem, L. Froehly, A. Seifert, and H. Zappe, "Scanning and tunable micro-optics for endoscopic optical coherence tomography," J. Microelectromech. Syst., vol. 20, no. 6, pp. 1462-1472, Dec. 2011.

[16] C. L. Arrasmith, D. L. Dickensheets, and A. Mahadevan-Jansen, "MEMSbased handheld confocal microscope for in-vivo skin imaging," Opt. Exp., vol. 18, no. 4, pp. 3805-3819, Feb. 2010.

[17] Y. Du, G. Zhou, K. L. Cheo, Q. Zhang, H. Feng, and F. S. Chau, "A 2-DOF circular-resonator-driven in-plane vibratory grating laser scanner," J. Microelectromech. Syst., vol. 18, no. 4, pp. 892-904, Aug. 2009.

[18] Y. Du, G. Zhou, K. L. Cheo, Q. Zhang, H. Feng, and F. S. Chau, "Doublelayered vibratory grating scanners for high-speed high-resolution laser scanning," J. Microelectromech. Syst., vol. 19, no. 5, pp. 1186-1196, Oct. 2010.

[19] X. Mu, G. Zhou, H. Yu, Y. Du, H. Feng, J. M. L. Tsai, and F. S. Chau, "Compact MEMS-driven pyramidal polygon reflector for circumferential scanned endoscopic imaging probe," Opt. Exp., vol. 20, no. 6, pp. 63256339, Mar. 2012.

[20] R. Hokari and K. Hane, "Micro-mirror laser scanner combined with a varifocal mirror," Microsyst. Technol., vol. 18, no. 4, pp. 475-480, 2012.

[21] R. A. Conant, P. M. Hagelin, U. Krishnamoorthy, M. Hart, O. Solgaard, K. Y. Lau, and R. S. Muller, "A raster-scanning full-motion video display using polysilicon micromachined mirrors," Sens. Actuators A, Phys., vol. 83, no. 1-3, pp. 291-296, May 2000.

[22] R. Hyejun, W. Piyawattanametha, Y. Taguchi, L. Daesung, M. J. Mandella, and O. Solgaard, "Two-dimensional MEMS scanner for dualaxes confocal microscopy," J. Microelectromech. Syst., vol. 16, no. 4, pp. 969-976, Aug. 2007.

[23] C. H. Manh and K. Hane, "Vacuum operation of comb-drive micro display mirrors," J. Micromech. Microeng., vol. 19, no. 10, pp. 105 018-107 000, Oct. 2009.

[24] H. M. Chu and K. Hane, "Design, fabrication and vacuum operation characteristics of two-dimensional comb-drive micro-scanner," Sens. Actuators A, Phys., vol. 165, no. 2, pp. 422-430, Feb. 2011.

[25] H. M. Chu, T. Tokuda, M. Kimata, and K. Hane, "Compact low-voltage operation micromirror based on high-vacuum seal technology using metal can," J. Microelectromech. Syst., vol. 19, no. 4, pp. 927-935, Aug. 2010.

[26] W. Piyawattanametha, P. R. Patterson, D. Hah, H. Toshiyoshi, and M. C. Wu, "Surface- and bulk-micromachined two-dimensional scanner driven by angular vertical comb actuators," J. Microelectromech. Syst., vol. 14, no. 6, pp. 1329-1338, Dec. 2005.

[27] A. Arslan, D. Brown, W. O. Davis, S. Holmstrom, S. K. Gokce, and H. Urey, "Comb-actuated resonant torsional microscanner with mechanical amplification," J. Microelectromech. Syst., vol. 19, no. 4, pp. 936-943, Aug. 2010.

[28] J.-W. Jeong, S. Kim, and O. Solgaard, "Split-frame gimbaled twodimensional MEMS scanner for miniature dual-axis confocal microendoscopes fabricated by front-side processing," J. Microelectromech. Syst., vol. 21, no. 2, pp. 308-315, Apr. 2012.

[29] F. Zimmer, M. Lapisa, T. Bakke, M. Bring, G. Stemme, and F. Niklaus, "One-megapixel monocrystalline-silicon micromirror array on CMOS driving electronics manufactured with very large-scale heterogeneous integration," J. Microelectromech. Syst., vol. 20, no. 3, pp. 564-572, Jun. 2011.

[30] D.-H. Kim, M.-W. Kim, J.-W. Jeon, K. S. Lim, and J.-B. Yoon, “Modeling, design, fabrication, and demonstration of a digital micromirror with interdigitated cantilevers," J. Microelectromech. Syst., vol. 18, no. 6, pp. 13821395, Dec. 2009.

[31] K. Isamoto, K. Totsuka, T. Suzuki, T. Sakai, A. Morosawa, C. Chong, H. Fujita, and H. Toshiyoshi, "A high speed MEMS scanner for 140-kHz SS-OCT," in Proc. IEEE Int. Conf. Opt. MEMS Nanophoton., Istanbul, Turkey, 2011, pp. 73-74.

[32] K. Jia, S. Pal, and H. Xie, "An electrothermal tip-tilt-piston micromirror based on folded dual S-shaped bimorphs," J. Microelectromech. Syst., vol. 18 , no. 5, pp. 1004-1015, Oct. 2009. 
[33] A. Jain, H. W. Qu, S. Todd, and H. Xie, "A thermal bimorph micromirror with large bi-directional and vertical actuation," Sens. Actuators A, Phys., vol. 122, no. 1, pp. 9-15, Jul. 2005.

[34] J. J. Sun, S. G. Guo, L. Wu, L. Liu, S. W. Choe, B. S. Sorg, and H. Xie, "3D in vivo optical coherence tomography based on a low-voltage, largescan-range 2D MEMS mirror," Opt. Exp., vol. 18, no. 12, pp. $12065-$ 12075 , Jun. 7, 2010.

[35] K. Jia, S. R. Samuelson, and H. Xie, "High-fill-factor micromirror array with hidden bimorph actuators and tip-tilt-piston capability," J. Microelectromech. Syst., vol. 20, no. 3, pp. 573-582, Jun. 2011.

[36] S. Pal and H. Xie, "A curved multimorph based electrothermal micromirror with large scan range and low drive voltage," Sens. Actuators A, Phys., vol. 170 , no. $1 / 2$, pp. 156-163, Nov. 2011.

[37] L. Li, V. Stankovic, L. Stankovic, L. Li, S. Cheng, and D. Uttamchandani, "Single pixel optical imaging using a scanning MEMS mirror," $J$. Micromech. Microeng., vol. 21, no. 2, p. 025022, Feb. 2011.

[38] H. Urey, S. Holmstrom, and A. D. Yalcinkaya, "Electromagnetically actuated FR4 scanners," IEEE Photon. Technol. Lett., vol. 20, no. 1, pp. 30-32, Jan. 2008.

[39] A. D. Yalcinkaya, H. Urey, D. Brown, T. Montague, and R. Sprague, "Two-axis electromagnetic microscanner for high resolution displays," J. Microelectromech. Syst., vol. 15, no. 4, pp. 786-794, Aug. 2006.

[40] Y. D. Gokdel, B. Sarioglu, S. Mutlu, and A. D. Yalcinkaya, "Design and fabrication of two-axis micromachined steel scanners," J. Micromech. Microeng., vol. 19, no. 7, pp. 075001-1-075001-8, Jul. 2009.

[41] H. Miyajima, N. Asaoka, T. Isokawa, M. Ogata, Y. Aoki, M. Imai, O. Fujimori, M. Katashiro, and K. Matsumoto, "A MEMS electromagnetic optical scanner for a commercial confocal laser scanning microscope," J. Microelectromech. Syst., vol. 12, no. 3, pp. 243-251, Jun. 2003.

[42] A. D. Yalcinkaya, O. Ergeneman, and H. Urey, "Polymer magnetic scanners for bar code applications," Sens. Actuators A, Phys., vol. 135, no. 1, pp. 236-243, 2007.

[43] A. D. Yalcinkaya, H. Urey, and S. Holmstrom, "NiFe plated biaxial MEMS scanner for 2-D imaging," IEEE Photon. Technol. Lett., vol. 19, no. 5, pp. 330-332, Mar. 2007.

[44] T.-L. Tang, C.-P. Hsu, W.-C. Chen, and W. Fang, "Design and implementation of a torque-enhancement 2-axis magnetostatic SOI optical scanner," J. Micromech. Microeng., vol. 20, no. 2, pp. 025020-025027, Feb. 2010.

[45] K. H. Koh, T. Kobayashi, F.-L. Hsiao, and C. Lee, "Characterization of piezoelectric PZT beam actuators for driving 2D scanning micromirrors," Sens. Actuators A, Phys., vol. 162, no. 2, pp. 336-347, May 2010.

[46] K. H. Koh, T. Kobayashi, J. Xie, A. Yu, and C. Lee, "Novel piezoelectric actuation mechanism for a gimbal-less mirror in 2D raster scanning applications," J. Micromech. Microeng., vol. 21, no. 7, p. 075001, Jul. 2011.

[47] K. H. Koh, T. Kobayashi, and C. Lee, "A 2-D MEMS scanning mirror based on dynamic mixed mode excitation of a piezoelectric PZT thin film S-shaped actuator," Opt. Exp., vol. 19, no. 15, pp. 13812-13824, Jul. 2011.

[48] Y. Zhu, W. Liu, K. Jia, W. Liao, and H. Xie, "A piezoelectric unimorph actuator based tip-tilt-piston micromirror with high fill factor and small tilt and lateral shift," Sens. Actuators A, Phys., vol. 167, no. 6, pp. 495-501, Jun. 2011

[49] U. Baran, D. Brown, S. Holmstrom, D. Balma, W. O. Davis, A. Mazzalai, P. Muralt, and H. Urey, "High frequency torsional MEMS scanner for displays," in Proc. IEEE Int. Conf. Micro Electro Mech. Syst., Paris, France, 2012, pp. 636-639.

[50] T. Kobayashi, R. Maeda, T. Itoh, and R. Sawada, "Smart optical microscanner with piezoelectric resonator, sensor, and tuner using $\mathrm{Pb}(\mathrm{Zr}, \mathrm{Ti}) \mathrm{O}_{3}$ thin film," Appl. Phys. Lett., vol. 90, no. 18, pp. 183514-1183514-3, Apr. 2007

[51] M. Tani, M. Akamatsu, Y. Yasuda, H. Fujita, and H. Toshiyoshi, "A combination of fast resonant mode and slow static deflection of SOI-PZT actuators for MEMS image projection display," in Proc. IEEE/LEOS Int. Conf. Opt. MEMS, Big Sky, MT, 2006, pp. 25-26.

[52] P. J. Gilgunn, J. Liu, N. Sarkar, and G. K. Fedder, "CMOS-MEMS lateral electrothermal actuators," J. Microelectromech. Syst., vol. 17, no. 1, pp. 103-114, Feb. 2008.

[53] H. Xie, Y. Pan, and G. K. Fedder, "A CMOS-MEMS mirror with curled-hinge comb drives," J. Microelectromech. Syst., vol. 12, no. 5, pp. 450-457, Aug. 2003.

[54] A. Jain, A. Kopa, Y. Pan, G. K. Fedder, and H. Xie, "A two-axis electrothermal micromirror for endoscopic optical coherence tomography," IEEE J. Sel. Topics Quantum Electron., vol. 10, no. 3, pp. 636-642, May/Jun. 2004

[55] D. Lange, C. Hagleitner, C. Herzog, O. Brand, and H. Baltes, "Electromagnetic actuation and MOS-transistor sensing for CMOS-integrated micromechanical resonators," Sens. Actuators A, Phys., vol. 103, no. 1/2, pp. 150-155, Jan. 2003.
[56] I.-J. Cho, T. Song, S.-H. Baek, and E. Yoon, "A low-voltage and lowpower RF MEMS series and shunt switches actuated by combination of electromagnetic and electrostatic forces," IEEE Trans. Microw. Theory Tech., vol. 53, no. 7, pp. 2450-2457, Jul. 2005.

[57] W. Xiaochun, A. Khaligh, and X. Yang, "Modeling, design and optimization of hybrid electromagnetic and piezoelectric MEMS energy scavengers," in Proc. IEEE Cust. Integr. Circuits Conf., San Jose, CA, 2008, pp. $177-180$.

[58] B. Yang, C. Lee, W. L. Kee, and S. P. Lim, "Hybrid energy harvester based on piezoelectric and electromagnetic mechanisms," J. Micro./Nanolith., MEMS MOEMS, vol. 9, no. 2, pp. 023002-1-023002-10, Apr. 2010.

[59] G. Brown, L. Li, R. Bauer, J. Liu, and D. Uttamchandani, "A two-axis hybrid MEMS scanner incorporating electrothermal and electrostatic actuators," in Proc. IEEE Int. Conf. Opt. MEMS Nanophoton., Sapporo, Japan, 2010, pp. 115-116.

[60] L. Li, R. Bauer, G. Brown, and D. Uttamchandani, "A symmetric hybrid MEMS scanner with electrothermal and electrostatic actuators," in Proc. IEEE Int. Conf. Opt. MEMS Nanophoton., Istanbul, Turkey, 2011, pp. 163-164.

[61] C. Liu, Ed., Foundations of MEMS. Englewood Cliffs, NJ: Prentice-Hall, 2005 .

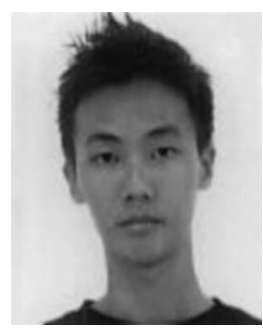

Kah How Koh (S'11) received the B.Eng.(Hons.) degree from the Department of Electrical and Computer Engineering, National University of Singapore, Singapore, in 2009, where he is currently working toward the Ph.D. degree in electrical engineering.

His research work is on the development of nove actuation mechanisms for optical microelectromechanical systems, focusing mainly on 2-D scanning and variable optical attenuation applications. He has contributed 17 peer-reviewed international journal and conference articles in the capacity of first author

Mr. Koh was the recipient of the Singapore Economic Development Board-GLOBALFOUNDRIES Graduate Scholarship for 2009-2013. He was also the recipient of the Best Paper Award and Best Student Paper of Section Award for the IEEE Photonics Global Conference 2010 and the 16th OptoElectronics and Communications Conference (OECC 2011), respectively.

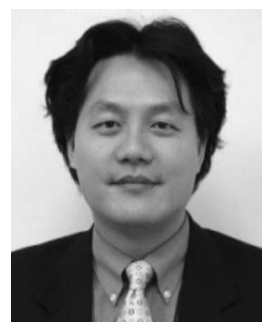

Chengkuo Lee (S'93-M'96) received the M.S. degree in materials science and engineering from $\mathrm{Na}-$ tional Tsing Hua University, Hsinchu, Taiwan, in 1991, the M.S. degree in industrial and system engineering from Rutgers University, New Brunswick, $\mathrm{NJ}$, in 1993, and the Ph.D. degree in precision engineering from The University of Tokyo, Tokyo, Japan, in 1996.

He was a Foreign Researcher in the Nanometerscale Manufacturing Science Laboratory at the Research Center for Advanced Science and Technology of The University of Tokyo from 1993 to 1996 . He had also worked in the Mechanical Engineering Laboratory, Advanced Industrial Science and Technology, Ministry of International Trade and Industry of Japan, as a Japan Science and Technology Research Fellow in 1996. Thereafter, he was a Senior Research Staff Member of the Microsystems Laboratory, Industrial Technology Research Institute, Hsinchu. In September 1997, he joined the Metrodyne Microsystem Corporation, Hsinchu, and established the MEMS Device Division and the first micromachining laboratory for commercial purposes in Taiwan. He was the Manager of the MEMS Device Division between 1997 and 2000. He was an Adjunct Assistant Professor in the Department of Electrophysics, National Chiao Tung University, Hsinchu, Taiwan, in 1998, and an Adjunct Assistant Professor in the Institute of Precision Engineering, National Chung Hsing University, Taichung, Taiwan, from 2001 to 2005. He cofounded Asia Pacific Microsystems, Inc. (APM), Hsinchu, in August 2001, and he became the Vice President of R\&D; then, later, until the end of 2005, he became the Vice President of the optical communication business unit and the Special Assistant to the Chief Executive Officer in charge of international business and technical marketing for MEMS foundry service at APM, Inc., one of the top 30 MEMS manufacturers in the world in 2004. From 2006 to 2009, he was a Senior Member of Technical Staff at the Institute of Microelectronics, $\mathrm{A} *$ Star, Singapore. He has been an Assistant Professor in the Department of Electrical and Computer Engineering, National University of Singapore, Singapore, since December 2005. He is the coauthor of the book Advanced MEMS Packaging (McGraw-Hill, 2010). He has contributed more than 140 international conference papers and extended abstracts, 100 peer-reviewed international journal articles, and nine U.S. patents in the MEMS, nanophotonics, and nanotechnology fields. 